\title{
Subject Placement in the History of Latin
}

\author{
Lieven Danckaert
}

CNRS/Université de Lille 3

lieven.danckaert@univ-lille3.fr

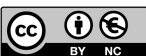

Received: May 2, 2017

Accepted: July 17, 2017

\begin{abstract}
The aim of this paper is to provide further support for one aspect of the analysis of Classical and Late Latin clause structure proposed in Danckaert (2017a), namely the diachrony of subject placement. According to the relevant proposal, one needs to distinguish an earlier grammar ('Grammar A', whose heyday is the period from ca. $200 \mathrm{BC}$ until $200 \mathrm{AD}$ ), in which there is no A-movement for subjects, and a later grammar ('Grammar B', which is on the rise from ca. 50-100 AD, and fully productive from ca. $200 \mathrm{AD}$ onwards), where subjects optionally move to the inflectional layer. Assuming the variationist acquisition model of language change developed in Yang (2000, 2002a,b), I present corpus evidence which confirms that it is only in the Late Latin period that TP-internal subjects fully establish themselves as a grammatical option.
\end{abstract}

Keywords: Latin; language change; word order; subject placement; grammar competition

\section{Resum. La posició del subjecte en la historia del llatí}

L'objectiu d'aquest article és proporcionar un suport addicional a un aspecte de l'anàlisi de l'estructura oracional del llatí clàssic i llatí tardà proposada a Danckaert (2017a), a saber, la diacronia de la posició del subjecte. D'acord amb la proposta rellevant, cal distingir una gramàtica anterior ('Gramàtica A', l'apogeu de la qual és aproximadament el període comprès entre el $200 \mathrm{aC}$ i el 200dC), en què no hi ha moviment-A per als subjectes, i una gramàtica posterior ('Gramàtica B', que sorgeix aproximadament el 50-100dC, i esdevé totalment productiva a partir del $200 \mathrm{dC}$ en endavant), on els subjectes es mouen opcionalment a la capa flexional. Assumint el model variacionista d'adquisició del canvi lingüístic desenvolupat a Yang (2000, 2002a,b), presento evidència de corpus que confirma que és només en el període del llatí tardà que els subjectes interns a l'ST s'estableixen plenament com una opció gramatical.

Paraules clau: llatí; canvi lingüístic; ordre de paraules; posició del subjecte; competència de gramàtiques 


\section{Table of Contents}

1. Introduction: subject placement in Latin and Romance

2. Latin clause structure in diachrony: a very brief summary of Danckaert (2017a)

3. Excursus: more on the syntax of VP-internal subjects

4. The 'variationist acquisition' approach to language change

(Yang 2000, 2002a,b)
5. Cues for VP-internal and TP-internal subjects

6. Subject placement in Classical and Late Latin: the corpus evidence

7. Conclusion

References

\section{Introduction: subject placement in Latin and Romance}

\subsection{The problem of structural ambiguity}

When trying to determine the syntactic structure of a given utterance, the syntactician routinely runs into problems of structural ambiguity, which we can informally describe as the potential for one and the same linear string of words to correspond to more than one well-formed syntactic structure. In the case of a language like Latin, where word order is very flexible, this problem is indeed quite pervasive. Let us for example assume that we want to study the structural position of subjects in Latin. Consider then a very short clause such as (1a), which features an inflected form of the unergative predicate rideo 'laugh' alongside a preverbal subject NP:
(1)
a. nemo ride-t
nobody.NOM laugh-PRS.3SG
'Nobody laughs.' (Sen. Con. 9.praef.3)

We know independently that at all stages of the Latin language, the T-node can either be head-final or head-initial (witness the availability of both VPAux and AuxVP-orders). In addition, as we will see in more detail below, subjects can either remain VP-internal or undergo A-movement to the TP-layer. Moreover, they can also be A'-moved to the left periphery (cf. Danckaert 2012). Assuming that finite verbs are located somewhere in the TP-layer ( $\mathrm{T}^{\circ}$ for the sake of simplicity), given the three parameters just mentioned (headedness of TP, \pm A-movement of $\mathrm{S}, \pm \mathrm{A}$ '-movement of S), we would have to assume that (1a) is at least seven-ways ambiguous. ${ }^{1}$ Concretely, and assuming for the time being fairly simple representations that I will further refine in the course of this paper, it is first of all possible that we are dealing with a structure with a head-initial T-node and a subject in SpecTP (cf. (1b)). In the string-identical (1c), we see a head-final TP, and a subject in VP.

1. In other words, given these three binary parameters, seven out of the eight combinatorial possibilities yield a linear SV-order, the only structure with a VS-order being one with a head-initial T and an in situ subject in SpecVP. 
This structure in turn differs minimally from (1d), in that here the subject has (string vacuously) moved to SpecTP. Finally, in (1e) to $(1 \mathrm{~g})$ we see the same structural configurations as in (1b) tot (1d), modulo the fact that in the last three cases the subject has been A'-moved to SpecCP, again without there being any difference qua linear word order. Finally, (1h) shows a structure which without A'-movement of the subject DP would have yielded a VS-order:
b. $\left[{ }_{\mathrm{CP}}\left[\left[_{\mathrm{C}},\left[_{\mathrm{TP}}\right.\right.\right.\right.$ nemo $\left.\left.\left.\left.\left[{ }_{\mathrm{T}}, \operatorname{ridet}\left[\mathrm{VP}_{\mathrm{S}} \mathrm{t}_{\mathrm{V}}, \mathrm{t}_{\mathrm{V}}\right]\right]\right]\right]\right]\right]$
c. $\left[_{\mathrm{CP}}\left[\left[_{\mathrm{C}},\left[_{\mathrm{TP}}\left[{ }_{\mathrm{T}},\left[_{\mathrm{VP}}\right.\right.\right.\right.\right.\right.$ nemo $\left.\left[\mathrm{V}, \mathrm{t}_{\mathrm{V}}\right]\right]$ ridet $\left.\left.\left.]\right]\right]\right]$
d. $\left[_{C P}\left[{ }_{C},\left[_{T P}\right.\right.\right.$ nemo $\left[{ }_{T},\left[{ }_{V P} t_{S}\left[{ }_{V}, t_{V}\right]\right]\right.$ ridet $\left.\left.\left.]\right]\right]\right]$
e. $\left[{ }_{C P}\right.$ nemo $\left[{ }_{C},\left[_{T P} t_{S},\left[{ }_{T}\right.\right.\right.$, ridet $\left.\left.\left.\left.\left[{ }_{V P} t_{S}\left[{ }_{V}, t_{V}\right]\right]\right]\right]\right]\right]$

f. $\left[{ }_{C P}\right.$ nemo $\left[{ }_{C},\left[_{T P}\left[{ }_{T},\left[{ }_{V P} t_{S}\left[t_{V}, t_{V}\right]\right]\right.\right.\right.$ ridet $\left.\left.\left.]\right]\right]\right]$

g. $\left[_{C P}\right.$ nemo $\left[{ }_{C},\left[_{T P} t_{S},\left[_{T},\left[{ }_{V P} t_{S}\left[v, t_{V}\right]\right]\right.\right.\right.$ ridet $\left.]\right]$

h. $\left[_{C P}\right.$ nemo $\left.\left[{ }_{C},\left[_{T P}\left[{ }_{T}, \operatorname{ridet}\left[{ }_{V P} t_{S}\left[{ }_{V}, t_{V}\right]\right]\right]\right]\right]\right]$ head-initial T, $\mathrm{S}$ in SpecTP head-final T, $\mathrm{S}$ in SpecVP head-final T, $\mathrm{S}$ in SpecTP

head-initial T, S A'-moved from SpecTP

head-final T, S A'-moved from SpecVP

head-final T, S A'-moved from SpecTP

head-initial T, S A'-moved from SpecVP

Consider next a comparable two-word utterance, which features the same predicate, but this time with a postverbal subject:
a. ris-it
Trimalchio
laugh-PRF.3SG Trimalchio.NOM
'Trimalchio laughed.' (Petr. 69.2)

Some possible parses of this example are listed below. Assuming again that the inflected verb standardly undergoes V-to-T movement, (2b) shows a structure with a head-initial TP and a subject in its VP-internal base position. (2c) minimally differs from the previous representation, in that the subject has been extraposed (simply represented here as having undergone rightward movement, and ending up right adjoined to TP), an operation which in this case does not alter the surface word order. Next, as we will see below, in Latin there is also more than one position for finite verbs. Let us assume for the moment that apart from the canonical position in $\mathrm{T}^{\circ}$, the verb can in addition undergo movement to the left periphery (an analysis that I will make more precise in section 2.2.2). In (2d-f) I show three structures involving this type of V-to-C movement, which again all involve exactly the same surface word order, but in which the subject appears in a different structural position, viz. in SpecVP (2d), in the right periphery (2e), and in SpecTP (2f): 
(2) b. $\left[{ }_{C P}\left[{ }_{C},\left[_{T P}\left[{ }_{T}\right.\right.\right.\right.$, risit $\left[{ }_{V P}\right.$ Trimalchio $\left.\left.\left.\left.\left.\left[{ }_{V}, t_{v}\right]\right]\right]\right]\right]\right]$

c. $\left[{ }_{C P}\left[{ }_{C},\left[\left[_{T P}\left[{ }_{T}\right.\right.\right.\right.\right.$, risit $\left.\left.\left[{ }_{V P} t_{s}\left[v, t_{v}\right]\right]\right]\right]$ Trimalchio $\left.\left.]\right]\right]$

d. $\left[{ }_{C P}\left[{ }_{C}\right.\right.$, risit $\left[{ }_{T P}\left[{ }_{T}, t_{v},\left[{ }_{V P}\right.\right.\right.$ Trimalchio $\left.\left.\left.\left.\left.\left[{ }_{V}, t_{v}\right]\right]\right]\right]\right]\right]$

e. $\left[{ }_{C P}\left[{ }_{C}\right.\right.$, risit $\left[\left[_{T P}\left[{ }_{T}, t_{v},\left[{ }_{V P} t_{s}\left[t_{V}, t_{v}\right]\right]\right]\right]\right.$ Trimalchio $\left.\left.]\right]\right]$

\section{f. $\left[\left[_{C P}\left[{ }_{C}, \operatorname{risit}\left[{ }_{T P}\right.\right.\right.\right.$ Trimalchio $\left.\left.\left.\left[{ }_{T}, t_{v},\left[_{V P} t_{s}\left[{ }_{V}, t_{v}\right]\right]\right]\right]\right]\right]$}

head-initial T, $\mathrm{S}$ in SpecVP

head-initial T, S extraposed

head-initial $\mathrm{T}, \mathrm{S}$ in SpecVP, V-to-C

head-initial $\mathrm{T}, \mathrm{S}$ extraposed, V-to-C

head-initial T, $\mathrm{S}$ in SpecTP, V-to-C

Note that the list in (2b-f) is not exhaustive, as the order 'verb - subject' can for example also involve a structure with a head-final TP and an extraposed subject. The basic point should however be clear: simple Latin clauses are multiple ways structurally ambiguous, and as a result, very short tokens do not typically inform the syntactician about general properties of Latin clausal syntax.

The standard solution to remedy this problem is to look at clauses which contain more material than just two or three (open class) lexical items. As will be detailed in section 5 of this paper, functional categories such as complementizers (subordinating conjunctions) and (non-circumstantial) adverbs can provide us with very useful clues about the delimitation of different 'zones' in the clause. For instance, a manner adverb, which for the sake of simplicity we can assume to be VP-adjoined, can help us to distinguish VP-internal subjects from subjects that have undergone A-movement to SpecTP. Another type of functional category whose presence reduces the number of possible phrase structure analyses of many a Latin clause is auxiliaries ${ }^{2}$ : not only does the relative ordering of an auxiliary and a dependent lexical verb (past participles or infinitive) inform us about the headedness of the T-node, the exact location of phrasal material with respect to these two verb forms can also provide us with information about the correct analysis of a given utterance.

Importantly, there can be no doubt that language acquiring children are confronted with exactly the same issue as the professional syntactician. As will be further elaborated on in section 4, there is every reason to assume that the language learner only sets syntactic parameters on the basis of unambiguous evidence, i.e. clauses which are not structurally ambiguous (with respect to one or more specific phenomena). We will see that such unambiguous tokens invariably contain one or more functional categories.

2. I use the term 'auxiliary' to informally refer to any functional (i.e. closed class) verb. Note however that I will only consider auxiliaries that appear in strictly monoclausal configurations. As argued at length in Danckaert (2017a: chapter 3), three such environments can be identified in Latin, namely clauses with a (passive or deponent) BE-periphrasis (BE-auxiliary + past participle), and clauses with the modal verbs possum 'be able' and debeo 'have to' and a dependent infinitive. 
Before spelling out exactly which question I will address in the present paper, let us first look at some evidence in favour of the claim that in Latin subject arguments can either surface in SpecVP or in SpecTP, or in other words, that there is no such thing as obligatory A-movement for subjects (despite the fact that the language does not have (overt) subject expletives).

\subsection{A first look at VP-internal subjects in Latin and Romance}

I will at this stage look at passive subjects (i.e. internal arguments) occurring in clauses with a passive BE-periphrasis. In the examples in (3), the subject NPs marked in boldface occur in a rightward position in what we can take to be a head-initial VP. In both examples the presence of an adverbial expression (underscored) to the left of the past participle suggests that the lexical verb itself sits in its base position, and thus that the order ' $\mathrm{PaPa}$ - subject' did not come about through movement of the lexical verb past an A-moved subject in some TP-internal specifier. ${ }^{3}$
a. quamquam $\left[_{\mathrm{TP}}\left[_{\mathrm{VP}}\right.\right.$ although
$\underline{\text { mal-e }}\left[_{V P}\right.$
gest-a
re-s]]
era-t]
nec gest-ur-os
done-NOM.F.SG matter-NOM be.IPFV-3SG

and.not do-PTCP.FUT-ACC.M.PL better.ADV hope-PRS.INF be.able-IPFV-3PL 'although the mission was a failure, and although they couldn't hope to fare better in a next battle' (Liv. 1.37.5)
b. $\operatorname{cum}\left[_{T P}\left[{ }_{V P}\left[_{A D V P}\right.\right.\right.$ celer-ius solit-o $]\left[_{V P}\right.$ duct-um agmen]] when fast-COMP.ADV usual-ABL led-NOM.N.SG army.NOM es-se-t] be-IPFV.SBJV-3SG

'when the army had moved more quickly than usual' (Liv. 22.14.1)

Even in the classical period, Latin also had unambiguously TP-internal subjects. For instance, in the examples in (4) the derived subjects res '(lit.) matter' and mors fili 'death of $<$ her $>$ son' not only appear preverbally, but also to the left of adverbs that we can take to be VP-adjoined:

3. Note that quamquam in (3a) means 'although' and not 'however (much)': given the latter reading, the conjunction would be a degree modifier that might form a left-peripheral constituent together with the adverb male 'badly' ('however badly the mission had been handled'). However, as in the second of the two conjoined clauses no gradable expression is present with which quamquam could possibly be associated, we can be confident that the bracketing given is indeed accurate. 
(4) a. si $\left[{ }_{\mathrm{TP}}\right.$ re-s $\left[\mathrm{VP}_{\mathrm{VP}}\right.$ prosper-e $\quad[\mathrm{VP}$ gest-a $\left.]\right] \quad$ es-se-t $]$ if matter-NOM successful-ADV done-NOM.F.SG be-IPFV.SBJV-3SG 'if the battle were to be successful' (Liv. 32.6.5)

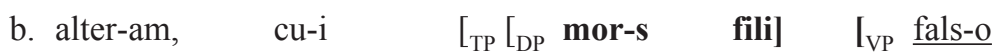
other-ACC.F.SG which-DAT.F.SG death-NOM son.GEN false-ADV [vp nuntiat-a]] era-t] reported-NOM.F.SG be.IPFV-3SG

'another woman, to whom the death of her son had falsely been reported' (Liv. 22.7.13)

Similar observations can be made in clauses with a head-initial T-node: in (5a) the presence of the temporal adverb adhuc 'until now' suggests that the subject bellum 'war' does indeed occur low in the structure, arguably in a VP-internal position. In contrast, in (5b) the subject castra 'camp' sits to the left of the passive BE-auxiliary sunt, which shows that it has evacuated the verb phrase.

a. Unde [ [TP est [VP adhuc [VP bell-um tract-um] from.where be.PRS.3SG until.now war-NOM prolonged-NOM.N.SG nisi ex retardation-e et mor-a]?

unless from slowing.down-ABL and delay-ABL

'What has caused the protraction of the war until now, if hesitation not and delays?' (Cic. Phil. 5.30)

b. <post>quam ad Vulturn-um flumen $\left[_{\mathrm{TP}}\right.$ castr-a $\mathrm{I}_{\mathrm{T}}$, sunt after near Vulturnus-ACC river.ACC camp-NOM be.PRS.3PL [VP posit-a]]] put-NOM.N.PL

'after a camp had been pitched near the Vulturnus river' (Liv. 22.14.1)

Although the empirical picture of subject placement in present day Romance languages is one of much variation, it does seem to be the case that the high and the low subject position are still available. ${ }^{4}$ For instance, in the Italian examples in (6) (based on Belletti 2004: 19), we see that the subject Maria occurs postverbally in the a-example, in between the weak quantifier tutto 'everything', which acts as the direct object, and the indirect object al direttore 'to the director'. In contrast, the subject appears to the left of the verb in the b-example, arguably in the canonical preverbal subject position:

4. In the present context it is of course impossible to do justice to the entire literature on subject placement in Romance. For a number of recent studies, the reader is referred to Cardinaletti (2004, 2014) (on (varieties of) Italian), Costa (2004) (on European Portuguese), Laenzlinger \& Soare (2005) (on Romanian), Lahousse (2006) (on French) and Ordóñez (2007) (on Spanish). 
(6)
a. Spieghe-rà tutto Maria al direttore.
explain-FUT.3SG everything Maria to.the director
'Maria will explain everything to the director.'
b. Maria spieghe-rà tutto al direttore.
Maria explain-FUT.3SG everything to.the director
'Maria will explain everything to the director.'

As shown in (7), evidence for the structurally low position of postverbal subjects in Italian comes from adverb placement: if a postverbal subject co-occurs with a low aspectual adverb such as completamente 'completely' (cf. Cinque 1999), the former has to follow the latter:
(7) Capi-rà < $\quad<$ completamente $>$ Maria $<*$ completamente $>$. understand-FUT.3SG completely Maria completely 'Maria will understand completely.' (cf. Belletti 2004: 19, her examples (3a) and (4a))

There are two families of analyses of the pattern in which the subject appears low in the structure. According to the first, a postverbal subject appears in its VP-internal base position (see among many others Rizzi 1982, Burzio 1986 and Longobardi 2000 on Italian; Costa 2004 on European Portuguese). According to the second, postverbal subjects have undergone short movement to the edge of the VP-layer, to wind up in a specialized low focus projection (see Belletti 2001, 2004 on Italian, and Lahousse 2014 on French). ${ }^{5}$ In section 2.4 I will briefly come back to the question as to which analysis is on the right track.

\subsection{Aims of the paper}

The main hypothesis to be entertained in this paper is that the alternation between the patterns of subject placement illustrated in (3)-(5) does not remain stable throughout the lifespan of the Latin language, but rather, that the 'suject in TP' pattern in $(4) /(5 b)$ is an innovative variant. This proposal is in line with a series of proposals put forward in Danckaert (2017a), which will be introduced in section 2. The present paper moves beyond Danckaert (2017a) in that it analyses the positional distribution of external arguments rather than derived subjects such as the ones in examples (3)-(5) above.

The discussion is organized as follows. In sections 2 and 3 I detail my basic assumptions about clause structure in the history of Latin. In section 4 , I elaborate

5. As argued in Longobardi (2000) and Lahousse (2006), one needs to distinguish 'genuine inversion' (i.e. the VP-internal pattern which is variously analyzed as being base generated as such, or as derived through short focus movement) from 'focus inversion' (in Lahousse's terms). In the latter case the subject does not appear in the VP-layer, but rather has been extraposed (the surface order 'verb - subject' coming about through left-peripheral focus movement of the subject followed by remnant topicalization of the entire TP). On subject extraposition in Latin, see section 5.1.2. 
on one particular model of syntactic change, namely the variationist acquisition model proposed in Yang (2000, 2002a,b). Next, I detail which type of evidence could provide children acquiring Latin with unambiguous evidence for the grammar with subject movement to the TP-layer, and for the one without (section 5). Finally, in section 6 I assess whether the corpus data lend support to the basic claim of this paper, namely that optional A-movement for subjects is only characteristic of the grammar of Late Latin. Section 7 is a brief conclusion.

\section{Latin clause structure in diachrony: a very brief summary of Danckaert (2017a)}

\subsection{Background: the parameterized EPP}

One of the core proposals in Danckaert (2017a) is that it is necessary to distinguish two 'competing' grammars in the history of Latin, which crucially allow for different patterns of subject placement. The theoretical background of the proposal is a parameterized model of EPP-satisfaction first proposed in Alexiadou \& Anagnostopoulou (1998), and further elaborated on in Biberauer (2003). The basic idea is that is possible to maintain that there is a universal EPP-requirement, but that the languages of the world can make use of different resources to meet this requirement.

Concretely, we can assume that every (non-defective) clause is endowed with a functional projection which has to be overtly lexicalized by some $\varphi$-feature bearing category. Here I will call the relevant projection 'FP', and I will characterize it as a functional projection in the high middle field. FP comes with an EPP-feature which in the syntax acts as a Probe in need of a matching Goal. Two basic parameters govern the way in which the needs of this Goal can be satisfied, yielding a four-way typology. The first parameter says that the F-head can either probe for an $\mathrm{X}^{\circ}$ or an XP-category, and second parameter specifies that once probed for, the moving goal can or cannot pied-pipe additional material. When we cross-tabulate these two binary parameters, we arrive at the taxonomy summarized in Table 1.

Let me briefly comment upon this four-way taxonomy, starting with the options in which the attracted Goal does not pied-pipe anything (top row in Table 1). The head movement option always leads to verb movement to $\mathrm{F}$, and this typically happens in languages with rich subject-verb agreement (i.e. languages in which inflected verbs are endowed with a set of $\varphi$-features, such as (Standard) Italian and

Table 1. Parameters of EPP-checking (adapted from Biberauer and Roberts 2005; Biberauer and Richards 2006)

\begin{tabular}{lll}
\hline & \multicolumn{1}{c}{ Goal $=\mathbf{X}^{\circ}$} & \multicolumn{1}{c}{ Goal $=$ XP } \\
\hline - pied-piping & $\begin{array}{l}\text { V-to-F movement (with optional } \\
\text { DP movement to SpecSubjP) }\end{array}$ & $\begin{array}{l}\text { DP movement to (or expletive } \\
\text { insertion in) SpecFP }\end{array}$ \\
+ pied-piping & VP movement to SpecFP & DP or VP movement to SpecFP \\
\hline
\end{tabular}


Modern Greek). These languages allow for preverbal subjects, but A-movement of subjects in these languages is strictly speaking unrelated to the EPP, and it also targets a higher projection than the one hosting the EPP-feature. With Cardinaletti (2004), I will call this projection SubjP, and I will assume that it is an A-position rather than an A'-position. Next, the 'XP-Goal' option leads to displacement of the hierarchically highest argument XP (the 'subject') to SpecFP, or, as a last resort, to insertion of an expletive in the same locus: English is a language which is characterized by these parameter settings. In languages which have the second parameter set at the value [+ pied-piping] (bottom row of Table 1), EPP-satisfaction always comes about through phrasal movement to SpecFP, regardless of whether the element originally probed for is a head or a phrase. Without going into full details, suffice it to say that certain Germanic languages such as (Standard) German always satisfy the EPP-requirement through VP movement, witness the obligatory VPAux-order characteristic of the language. Other languages are more flexible, in that they allow for both VP and DP movement: (Colloquial) Afrikaans can be said to be such a language. The reader is referred to Biberauer (2003), Biberauer \& Roberts (2005) and Biberauer \& Richards (2006) for more detailed discussion of the original proposal.

In what follows, I will elaborate on my own application of this system to the syntax of the Latin clause, as developed in Danckaert (2017a). In a nutshell, the core proposal is that an earlier grammar ('Grammar A') employs VP movement to SpecFP to satisfy the EPP-requirement (see also Mackenzie \& van der Wurff 2012), and that a later grammar ('Grammar B') uses verb movement to F to do the same. Crucially, the earlier grammar does not have any sort of subject movement to the TP-layer, in contrast with the later grammar, which does in fact allow for optional A-movement to SubjP. As shown in Danckaert (2017a: 213; 261-262), Grammar B becomes fully productive in the second half of the $1^{\text {st }}$ century AD, but it may very well be the case that it was first actuated much earlier, probably even before $200 \mathrm{AD}$. In the later stages of the language (say the period from 200 to $600 \mathrm{AD}$ ), Grammar B is clearly the predominant one. Here I will only be concerned with the synchronic syntax of Grammar A and Grammar B: I refer once again to Danckaert (2017a) for discussion about the way in which Grammar B came into being.

Before we start the discussion, let me point out one important difference between Grammar A and Grammar B, which was discussed earlier in Danckaert (2017a: chapter 4; to appear a). Although the two grammars can generate on the one hand both VPAux and AuxVP-orders, and on the other hand also the orders $\mathrm{OV}$ and VO, in Grammar B the order VO cannot cooccur with the order VPAux. In contrast, Grammar A can in fact generate the order 'VOAux', witness the relatively high frequencies at which this pattern is attested in certain authors from especially the $1^{\text {st }}$ century AD. After $250 \mathrm{AD}$ however, the VOAux-pattern is almost completely absent. As a result, one will have to characterize the properties of Grammar A in such a way that this grammar can generate VOAux-orders. Conversely, our analysis of Grammar B should be able to capture the absence of this word order pattern in Late Latin. 


\subsection{Grammar A: VP movement to SpecFP}

As mentioned, both Grammar A and Grammar B can produce VPAux and AuxVPorders, but importantly, the underlying syntax of the resulting surface strings is very different, which is why I will treat the two separately. I will start with VPAuxclauses as generated by Grammar A.

\subsubsection{VPAux-orders}

I will assume that a Latin clause minimally consists of the following set of projections. At the bottom, there is an articulated thematic domain consisting of three layers, with first of all an a-categorial root (which can take an internal argument as its complement); next we find a verbalizing head $v$ and on top of this a Voice projection, whose head position is (at least in Latin) never overtly realized, but in whose specifier an agentive external argument can be introduced. Moving then to the inflectional layer, we have TP (whose head position I take to be lexicalized by an auxiliary, if present, or otherwise by a single synthetic verb after V-to-T movement), NegP, FP (i.e. the head associated with the EPP-feature), and finally the left periphery, the whole of which I represent as $\mathrm{CP}$, which is of course shorthand for a more articulated structure.

We can now offer a precise characterization of the structure of a VPAux-clause as generated by Grammar A. In this grammar the F-head probes for a phrasal category, and enters into an Agree relation with the hierarchically highest DP in the thematic domain (the external argument in an active clause, the internal argument in the case of passive and unaccusative predicates), which pied-pipes the entire verb phrase (VoiceP to be more precise) to SpecFP. ${ }^{6}$ All this is summarized in the tree in (8) (overt terminals in boldface): ${ }^{7}$

6. Note that this analysis entails a slight departure from the system laid out in section 2.1 , in that Grammar A is characterized as language where an XP is probed for and the pied-piping parameter is set at a positive value, without this giving rise to any optionality as to the type of category that can move to SpecFP (DP movement not being an available option). See Danckaert (2017a: 236-247) for extensive discussion. The conclusion that will be arrived at at the end of this paper suggests that this line of reasoning is indeed on the right track.

7. In this and the following tree structures I do not represent bar levels of projections which do not have any overtly lexicalized specifier: for instance, in (8) $\mathrm{Neg}^{\circ}$ projects straight up to NegP, rather than to Neg'. 


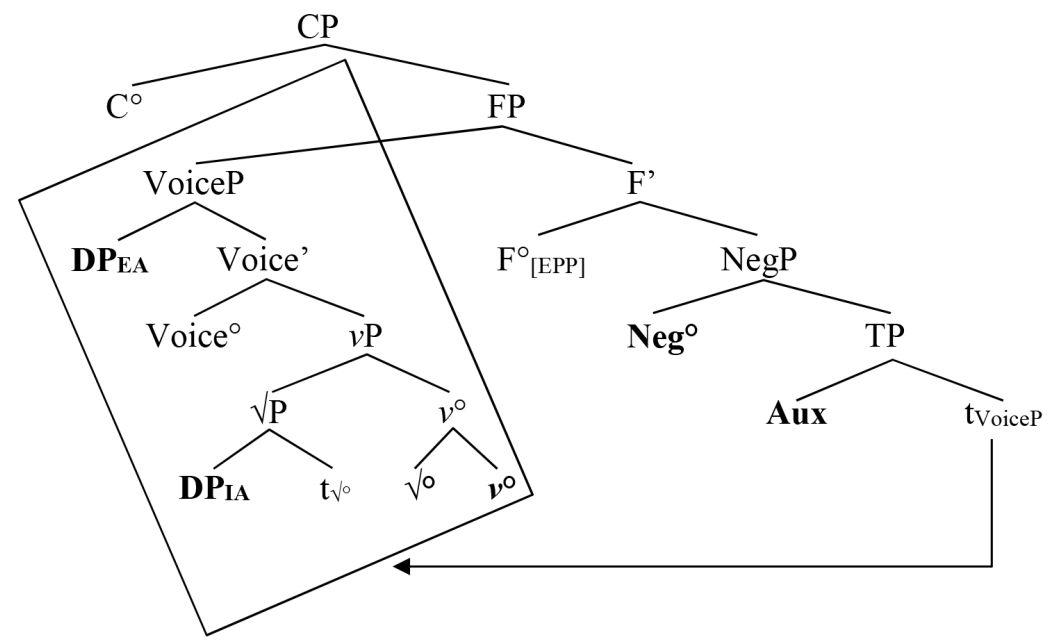

One of the most prominent features of this structure is that the T-node hosting the auxiliary does not c-command the verb phrase: rather the latter is displaced to a position above TP. As a result, 'VP-Aux' sequences are not subject to the 'FinalOver-Final Constraint' (FOFC for short, cf. Biberauer, Holmberg \& Roberts 2014), which rules out structures in which a head-final projection dominates a head initial one (within a given extended projection). Put differently, as VPAux-clauses in Grammar A do not involve a head-final TP (contrary to what one might initially think), VOAux-orders are correctly predicted to be grammatical in Grammar A, as desired. In addition, note that the structure in (8) also contains a negator, which is represented as a (free standing, i.e. non-proclitic) head $\mathrm{Neg}^{\circ}$, which in Latin is canonically lexicalized by the morpheme non 'not'. I refer to Danckaert (2017a: 51-60) for a series of arguments in favour of the claim that in Classical Latin, non is indeed a head rather a phrasal specifier. As shown there, this analysis correctly predicts that the hierarchically highest verb of a given clause cannot head move past negation (by virtue of the Head Movement Constraint), witness for example the absence of clauses where non appears at the very end of a clause.

Finally, observe that in the structure in (8), the external argument in SpecVoiceP remains in its base position throughout the derivation: as it happens, there is indeed no landing site projected to which it could move (abstracting away from left-peripheral movements of various types, whose availability is orthogonal to the point at issue, viz. A-movement to the TP-layer). Recall that the aim of this paper is to gather further support for this particular part of the characterization of Latin clause structure offered in Danckaert (2017a). I will further elaborate on the proper analysis of VP-internal subjects in section 3 below.

\subsubsection{AuxVP-orders}

Given the parameterized EPP-system outlined above, one has to assume that in a Grammar A setting VP movement to SpecFP is the only available option to satisfy the EPP-requirement, as the system does not allow for any optionality. In principle, 
this would leave us with a grammar that can only generate VPAux-orders. However, there is no historical stage on record in which AuxVP-clauses are absent in Latin (and there also do not seem to be any reasons to reconstruct a pre-historical stage of this type). In order to reconcile the existence of (very) early AuxVP-clauses with the assumption that in Early and Classical Latin, Grammar A was the most prevalent one, it was proposed in Danckaert (2017a) that at the very least a substantial subset of early AuxVP-clauses do actually involve EPP-driven VP movement, whose surface effect on word order is masked by a subsequent operation of auxiliary raising targeting a position which is higher than FP, and which I will simply label ' $G(P)$ '. Although it very much remains to be elucidated what triggers verb movement to $G$, and whether this operation is associated with any interpretive effect, suffice it to say that verb movement to $\mathrm{G}$ is not in any way related to EPP-satisfaction (although head movement to $\mathrm{G}$ does in fact pass through F: see Danckaert (2017a: 257-259) on this particular issue).

There are two pieces of empirical evidence in support of this proposal. First, as shown in detail in Danckaert (2017a: 220-224), there is a difference between early and late AuxVP-clauses with respect to the likelihood for the two elements 'Aux' and ' $\mathrm{V}$ ' to be linearly adjacent. In particular, earlier 'Aux-V' sequences are more likely to be interrupted by one or more intervening constituents, an observation which is compatible with the claim that especially in earlier AuxVP-clauses, the auxiliary is likely to sit in the higher G-projection. As we will see in section 2.2.2 below, in the second type of AuxVP-clause, which only becomes productive in later stages, auxiliaries canonically sit in $\mathrm{F}^{\circ}$. The second piece of evidence for the existence of two distinct positions for finite ${ }^{8}$ verbs - auxiliaries and synthetic lexical verbs alike - comes from adverb placement. The basic data are illustrated in (9)-(11). In each of these minimal pairs, we see the order 'aspectual adverb - finite verb' in the a-example, and the reverse order in the b-example. In addition, as shown in Danckaert (2017a: 26-27; 217-218), finite verbs can also occur both before and after modal adverbs such as fortasse 'maybe' and profecto 'certainly'.

a. mor-s $[\ldots]$, qu-ae ciu-ibus Roman-is semper fu-it death-NOM which-NOM.F.SG citizens-DAT Roman-DAT always be-PRF.3SG seruitut-e potior

slavery-ABL preferable.NOM

'death, which for Roman citizens has always been preferable to slavery' (Cic. Phil. 10.19)

b. Mitt-o re-m public-am, qu-ae fu-it semper omit-PRS.3SG matter-ACC public-ACC which-NOM.F.SG be-PRF.3sG always Sull-ae car-issim-a.

Sulla-DAT dear-SUP-NOM

'I do not mention the state, which was always most dear to Sulla.' (Cic. Sul. 75)

8. It may well be possible that the relevant generalization is to be formulated in such a way that it does not refer to finite verbs, but rather to the hierarchically highest verb of a given clause. I leave it for future research to investigate whether the alternation illustrated in (9)-(11) can also be observed in (fully propositional) non-finite clauses such as AcIs. 
(10)

a. quia plerumque eueni-t ut $[\ldots]$

because usually happen-PRS.3SG that

'because it usually happens that...' (Plin. Ep. 2.19.6)

b. sed eueni-t plerumque ut [...]

but happen-PRS.3SG usually that

'but it usually happens that' (Quint. 8.prooem.22)

(11) a. Ips-ae enim fer-ae null-o insequ-ent-e

self-NOM PRT wild.animals-NOM no.one-ABLfollow-PTCP.PRS-ABL.M.SG saepe incid-unt.

often fall.in-PRS.3PL

'For wild animals themselves often fall <into traps $>$ even if they're not being hunted down' (Cic. Off. 3.68)

b. Sed incid-unt saepe tempor-a cum [...].

but happen-PRS.3PL often times-NOM when

'But there are often times when...' (Cic. Off. 1.31)

Following Danckaert (2017a), I will interpret these data as follows. Assuming with Cinque (1999) that the relative ordering of (non-left-peripheral, non-extraposed) adverbs in the articulated TP-layer is universally fixed, it follows that the word order alternation under discussion is a matter of variable verb placement rather than variable adverb placement. In addition, if we want to maintain that all clauses in Grammar A are characterized by movement of VoiceP to SpecFP, we would have to assume that in Grammar A, the order AuxVP can only be derived by moving the hierarchically highest verb (an auxiliary in clauses with two verbs, the lexical verb in clauses with only one verb) to a position above FP. Let us call this position GP, and characterize it as a functional projection in the very high TP-layer, above modal adverbs, but still below FinP. The full structure of an AuxVP-clause in Grammar A is detailed in (12), which features two ${ }^{9}$ verb positions, one above and one below the functional space where modal and aspectual adverbs are first merged: 10

9. As hinted at earlier, and as we will see in more detail in the following section, in Grammar B the verb can also occur in $\mathrm{F}^{\circ}$.

10. Note however that in Cinque's (1999) hierarchy, two of the three Tense heads are higher than all of the Aspect heads: therefore one would have to conclude that what is labelled as $\mathrm{T}^{\circ}$ in (12) does not actually correspond to a designated Tense head from the Cinque hierarchy, but rather to some aspectual head which is at least as low a Cinque's 'Asp perfect ', whose specifier hosts the adverb always. The higher verb position $\mathrm{G}$ is probably at least as high a Cinque's $\mathrm{T}_{\text {past }}$ or $\mathrm{T}_{\text {future }}$. I will not here try to further clarify the 'cartography' of verb positions in the Latin clause. 


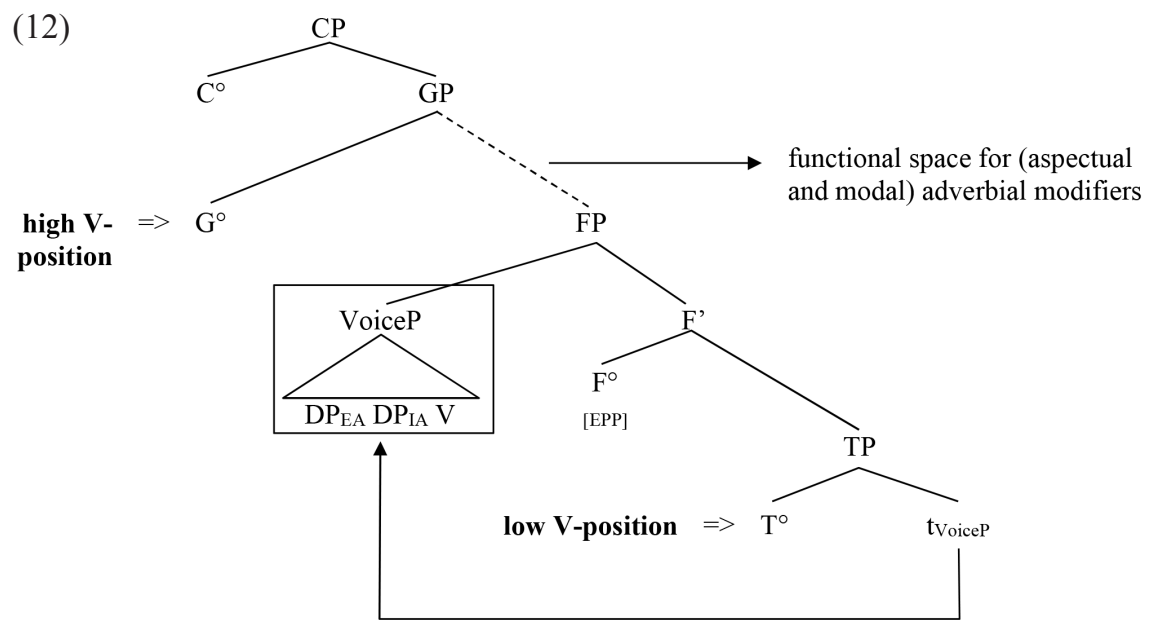

\subsection{Grammar B: V-to-F movement}

\subsubsection{VPAux-orders}

As mentioned in section 2.1, I take it that Grammar B differs from Grammar A in that EPP-checking happens through verb movement to $\mathrm{F}^{\circ} \cdot{ }^{11}$ In Danckaert (2017a), major difference between Grammar A and Grammar B is argued to be the status of the negator non: in the innovative grammar, this element is argued to be no longer a free standing $\mathrm{X}^{\circ}$-category, but rather a proclitic head which surfaces left adjacent to the hierarchically highest verb in the clause. As a result, in the presence of negation, verb movement to $\mathrm{F}$ passes through $\mathrm{Neg}^{\circ}$.

The basic structure of a VPAux-clause generated by Grammar B is given in (13). As the reader can observe, the 'high V-position' identified above is represented in this structure too (viz. above SubjP), a point to which I will come back below.

11. I refer to Danckaert (2017a: 254-255) for some speculation on the relation between this additional step of verb movement and the genesis of 'verb second(-like)' grammars in Early Romance. 


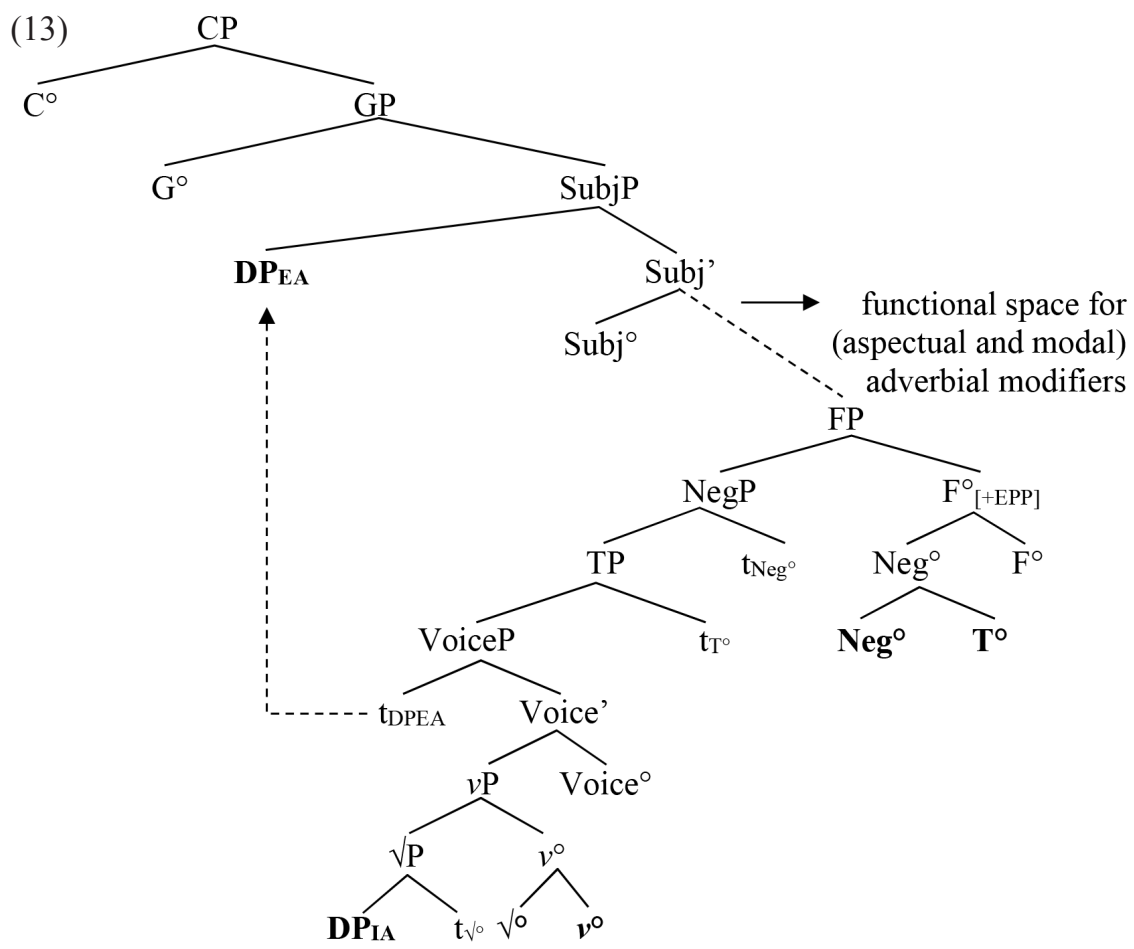

As can be observed, largely for the sake of simplicity I here represent complement-head sequences (i.e. head-final projections) as base generated rather than derived through movement (which would be in line with Kayne's (1994) antisymmetry hypothesis). In any event, in this structure the verb phrase (VoiceP) is dominated by all maximal projections of heads that at some point of the derivation can host auxiliaries, viz. TP, NegP and FP (and perhaps also GP, cf. the following section). The major advantage of assuming this type of structure is that it correctly derives the decline of the FOFC-violating order 'VOAux', which as mentioned is increasingly rare in Late Latin. In Grammar B, within one and the same extended projection, all projections dominated by a given head-final projection have to be themselves head-final too. It follows that for example a head-final TP cannot dominate a head-initial $\sqrt{\mathrm{P}}, \nu \mathrm{P}$ and/or VoiceP.

Finally, one last prominent difference between the structure in (13) and those generated by Grammar A which were reviewed above is the presence of a specialized projection 'SubjP' above FP but lower than the left periphery (cf. Cardinaletti 2004). As indicated by the dashed arrow, subject arguments can - apparently fully optionally - A-move to this projection. The remainder of this paper is devoted to mustering further support for the claim that the availability of this particular operation is one of the major differences between the grammars of earlier and later Latin. 


\subsubsection{AuxVP-orders}

Turning then to AuxVP-clauses in Grammar B, we can simply assume that these have essentially the same structure as VPAux-clauses in this grammar, modulo the different direction of complementation in a number of functional projections in the TP-layer. The structure of a clause featuring the word orders SAuxOV (with A-movement) and AuxSOV (without A-movement) is given in (14):

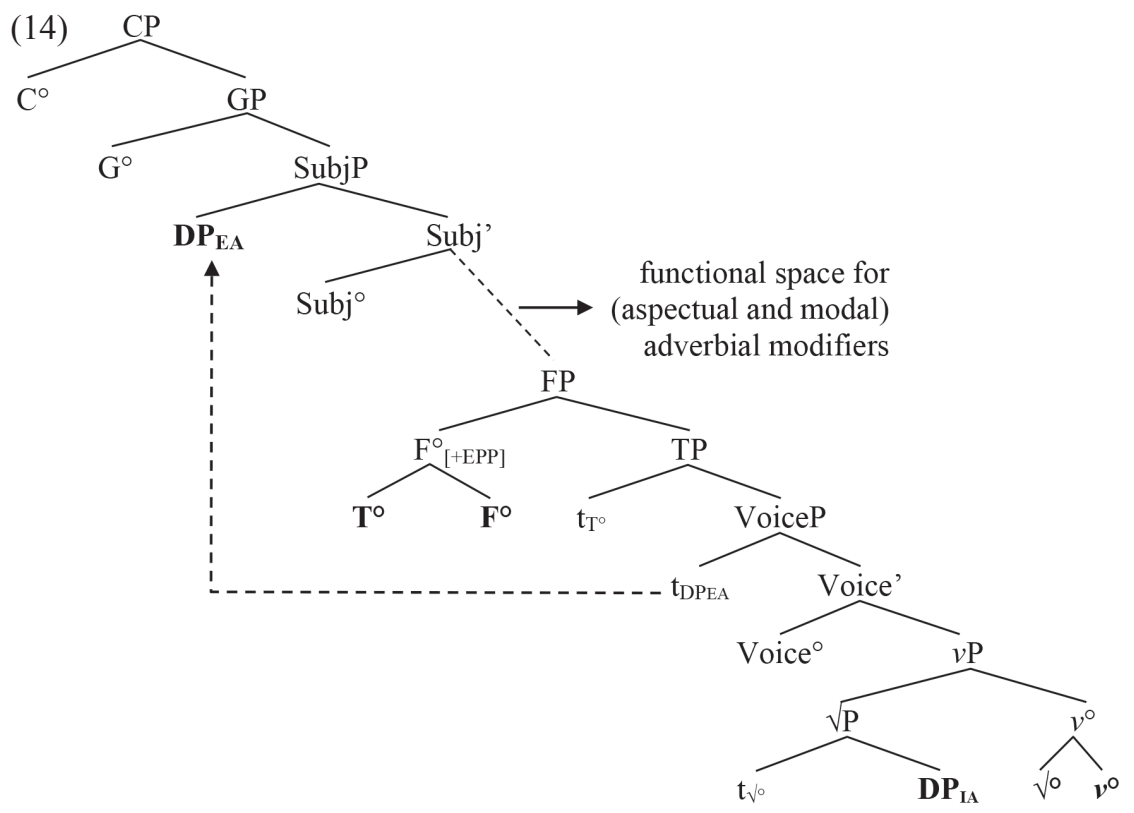

One important question that arises at this point is whether the operation of verb movement to $G$ is still available in Grammar B (as the trees in (13) and (14) suggest). Assuming that A-movement of subjects, as exemplified by clauses featuring the order 'subject XP - adverb', is a reliable indication that a given clause was generated by Grammar B, and assuming the order 'finite verb (auxiliary) adverb' to be indicative of movement to $G$, all we have to do is verify whether the two phenomena can cooccur. As exemplified by clauses featuring the late $2^{\text {nd }}$ century AD example in (15), which features the order 'AuxS-Adv-OV', they can:

(15) quia $\left[_{\mathrm{GP}}\right.$ pot-est $\quad\left[_{\text {SubjP }}\right.$ aduersari-us interdum $_{\text {[facil-ius }}$ because be.able-PRS.3SG opponent-NOM meanwhile easy-COMP.ADV VVoiceP $_{\mathrm{i}} \mathrm{t}_{\mathrm{id}}$ praesta-re $\left.\left.\left.]\right]_{]}\right]\right]_{3}$

this.ACC.N.SG provide-PRS.INF

'because the opposite party can in the meanwhile more easily provide this' (Gaius Inst. 4.53d) 
As it happens, my corpus (which I will further introduce in section 6.1) does not contain any examples where an auxiliary and a(n unambiguously non-left-peripheral) subject precede one or more adverbs, in such a way that the subject ends up to the left of the auxiliary. I will therefore conclude that GP is higher than SubjP, as suggested by the labels in (15). ${ }^{12}$ As will become clear in section 5, this conclusion has important repercussions for the way in which different patterns of subject placement are cued to the language learner. On the other hand, what we do find is the order ' $\mathrm{C}-\mathrm{S}-\mathrm{Adv}-\mathrm{Aux}-\mathrm{V}$ ', as in (16), where the modal verb possum 'be able' occurs below the aspectual adverb celerius 'quicker':
(16) ut conuers-os anim-os popul-orum etiam $\left[_{\text {Subjp }}[\right.$ nostr-a so.that converted-ACC minds-ACC people-GEN also our-NOM

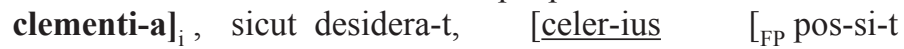 clemency-NOM as desire-PRS.3SG quick-COMP.ADV be.able-PRS.SBVJ-3SG [VoiceP $\mathrm{t}_{\mathrm{i}}$ agnosc-ere $\left.\left.\left.]\right]\right]\right]$ recognize-PRS.INF

'so that our Clemency, as he desires, may find out more quickly about the conversion of the people' (Gesta Conlationis Carthaginiensis 3.29, p. 1000, 11. 34-35 (Lancel))

If the bracketing provided for this example is correct, we would have to conclude that the functional space occupied by aspectual and modal adverbs is between FP and GP (as in (12)), not between TP and FP. As a result, verb movement to F does not result in 'V/Aux - aspectual/modal adverb' orders; rather, this last pattern always involve verb movement to $\mathrm{G}$.

\subsection{Interim conclusion: two grammars of subject placement}

To sum up this second section, I have spelled out a number of assumptions on Latin clause structure that allows us to make sense of the contrasting patterns of subject placement illustrated in (3) and (4). Specifically, I have distinguished a grammar in which A-movement to SubjP is possible and one where it is not. In both grammars, it is of course possible that the subject eventually ends up in some (left or right-) peripheral position. We have also seen that there are (at least) three positions for finite verbs (viz. T (in Grammar A), F (in Grammar B) and G (in both grammars)), an observation that will be important later on in the discussion. At various points, adverbs were used as probes into clause structure.

As mentioned at the end of section 1, the goal of this paper is to shed light on the diachronic development of subject placement in the history of Latin. Given the set of assumptions about Latin clause structure that we have just spelled out, we can now formulate this research question in more precise terms.

12. Should it in the end turn out that the order ' $\mathrm{C}-\mathrm{S}-\mathrm{Aux}-\mathrm{Adv}-\mathrm{V}$ ' (or perhaps the pattern ' $\mathrm{C}-\mathrm{S}-\mathrm{V}-\mathrm{Adv}$ ' more generally) is in fact attested outside my corpus, one would have to conclude that at least in Grammar B, there is yet another position for finite verbs. I hope to further look into this matter in future research. 
Given the system outlined in this section, Grammar A and Grammar B are concerned with the lexicalization of FP rather than with subject placement per se (although the two phenomena are clearly not unrelated). Recall also that in present day Romance, both VP and TP-internal subjects are available. The hypothesis that I would like to explore is that as a by-product of the genesis of Grammar B, two other grammars came into being, namely one in which subjects have to undergo A-movement, and one where they do not. Under this scenario, whether or not in a Grammar B setting a given subject XP undergoes A-movement is not a matter of 'true optionality' (in the sense of Biberauer \& Richards 2006), but rather a case of grammar competition (in the sense of Kroch 1989, 1994). It seems reasonable to hypothesize that in the long run the outcome of this process of grammar competition is (functional) specialization of both competing variants (in that VP-internal and TP-internal subjects both come to be associated with different discourse interpretations (low subjects probably being more 'focus-like', and high ones more 'topic-like')), rather than the generalization of one variant at the expense of the other. Needless to add, this last point remains to be further explored.

In section 4, I will outline the details of a model that can help us to empirically assess the validity of the hypothesis that the [+ A-movement] grammar fully establishes itself only in the Late Latin period, in the context of an acquisition-based approach to language variation and change. Before going there, in the next section I will first address a question which was briefly touched upon in the opening section, namely whether VP-internal subjects sit in their thematic base position or rather in some low discourse-related projection. Special attention will be paid to the correct analysis of clauses featuring the word order 'VAuxSO'.

\section{Excursus: more on the syntax of VP-internal subjects}

\subsection{In situ or at the VP-edge?}

Before moving on, let us first have another look at the details of the VP-internal subject pattern, concentrating this time on external arguments. As was the case with the derived subjects in (3) and (5a), low adverbs can provide us with clues to unambiguously identify a VP-internal agentive subject (external argument). In (17) and (18), we see two clauses with an auxiliary (resp. BE and possum 'be able') and a transitive lexical verb. In both examples, an external argument (in boldface) appears to the right of a manner adverb (underscored):

si $[$ pr grat-e $\quad$ pi-e=que $\quad[$ qP qu-is
if grateful-ADV=and affectionate-ADV=and someone-NOM.M.SG REFL.ACC
prosecut-us] $\quad$ fu-isse-t
followed-NOM.M.SG be-PLPRF.SBJV-3SG
'should someone have approached him kindly and affectionately' (Suet. Aug.
$66.4)$



(18) quo $\left[_{V P}\right.$ facil-ius $\quad\left[\begin{array}{lll}V P & \text { uos } & \text { coniectur-am de }\end{array}\right.$ so.that easy-COMP.ADV you.NOM.PL inference-ACC about trienni-o et de tot-a Sicili-a fac-ere]] period.of.3.years-ABL and about whole-ABL Sicily-ABL make-PRS.INF pos-sit-is be.able-PRS.SBJV-2PL

'so that you may have an idea about $<$ the profits he made during $>$ his threeyear tenure, in the whole of Sicily' (Cic. Ver. 3.106)

Again I will simply assume that such adverbials are VP-adjuncts; in the above examples, we can be confident that the relevant items (grate pieque 'kindly and affectionately' and facilius 'more easily') are indeed located in their base position, given that they occur to the right of a subordinating conjunction such as $s i$ 'if' or quo 'so that', which as argued in Danckaert (2012) demarcates the lower edge of the clausal left periphery. ${ }^{13}$ In other words, in the case of (17) and (18), we can safely assume that the order 'manner adverb - subject XP' did not come about through left-peripheral fronting of the adverbials across a TP-internal subject.

One important question that we have to address at this point is whether what I have qualified above as 'VP-internal subjects' do indeed remain in their thematic base position, or whether they are actually short moved to a dedicated low topic or focus projection dominating VoiceP, à la Belletti $(2001,2004)$, which as we have seen above would still give rise to 'adverb - subject' orders (cf. example (7)). Put differently, these two possible syntactic structures would typically result in the same linear word orders. However, unlike present day Romance Latin has VPAux-orders, and in this particular syntactic context surface word order might actually inform us about the question at issue. Consider for instance the following example from Suetonius (ca. 120 AD), which features a clause with an analytic deponent BE-periphrasis, and the overall word order 'VAuxSO'. The subject is marked in boldface:

(19) [Context: In his discussion of the emperor's character, Suetonius mentions among things Claudius' propensity for paranoia and his occasional fits of temper. He then turns to his overall intellectual capacities, and specifically the question as to whether he really was, or only pretended to be stupid.]

Inter ceter-a in eo mirat-i sunt among other-ACC.N.PL in this.ABL.M.SG admired-NOM.M.PL be.PRS.3PL homin-es et obliuion-em et inconsideranti-am. people-NOM and forgetfulness-ACC and absent-mindedness-ACC 'Among other things people were amazed by both his forgetfulness and his absent-mindedness.' (Suet. Div. 39.1)

13. More precisely, in Danckaert (2012) subordinating conjunctions are argued to be located in Fin : evidence for this analysis comes from among other things the observation that left-peripheral foci invariably precede complementizer-like elements. 
Under one possible analysis of this example, both the subject and the object would be extraposed, whereby 'extraposition' either involves rightward movement and right adjunction to one of the highest projections of the clause (either a high TP-internal or some left-peripheral functional projection), or alternatively leftperipheral (focus) fronting and subsequent leftward movement of a remnant TP. ${ }^{14}$ However, as will be elaborated on in section 5.1.2, it is unlikely that the subject in this example has been extraposed, as multiple extraposition of argument XPs does not seem to be available (although there is no general ban on multiple extraposition of e.g. relative clauses). ${ }^{15}$ But then how are examples like (19) to be analysed? And in particular, is it possible to somehow characterize the subject in a VAuxSO-clause as 'VP-internal'?

Let us first of all have a look at the information structure properties of the elements in the relevant example. It seems reasonable to characterize the direct object et obliuionem et inconsiderantiam 'both his forgetfulness and his absentmindedness' as a new information focus, as the relevant properties of the emperor add to our understanding of the person's character, which is the main topic under discussion. ${ }^{16}$ On the other hand, the generic subject homines '(the) people' clearly only constitutes backgrounded information. If we then assume that we are dealing here with a clause generated by Grammar A, a possible phrase structure representation would be as in (20). In this structure, both the external and the internal argument have evacuated the verb phrase before the latter moves to SpecFP. The landing site of the two argument XPs could then be the low topic and focus projections from Belletti (2001, 2004). With Devine \& Stephens (2006), I will call these projections Top $v \mathrm{P}$ and FocvP:

14. On the merits of these two competing analyses, see among others Wallenberg (2015).

15. VAuxOS and VAuxSO-patterns in languages with a strictly head-final TP, such as Hindi-Urdu (Manetta 2012) and Bangla (Simpson \& Choudhury 2015), would then have to be analysed in such a way that the occurrence of multiple arguments to the right of an auxiliary does not come about through repeated application of either high rightward adjunction, or of left-peripheral fronting followed by remnant movement.

16. As documented in Danckaert (2012), by the early second century AD left-peripheral fronting of new information foci had already become obsolete in Latin. Note however that the analysis proposed there, which relates the loss of left-peripheral foci to the loss of EPP-driven VP movement predicts a structure like (20) not to be available. I leave this issue for future research. 


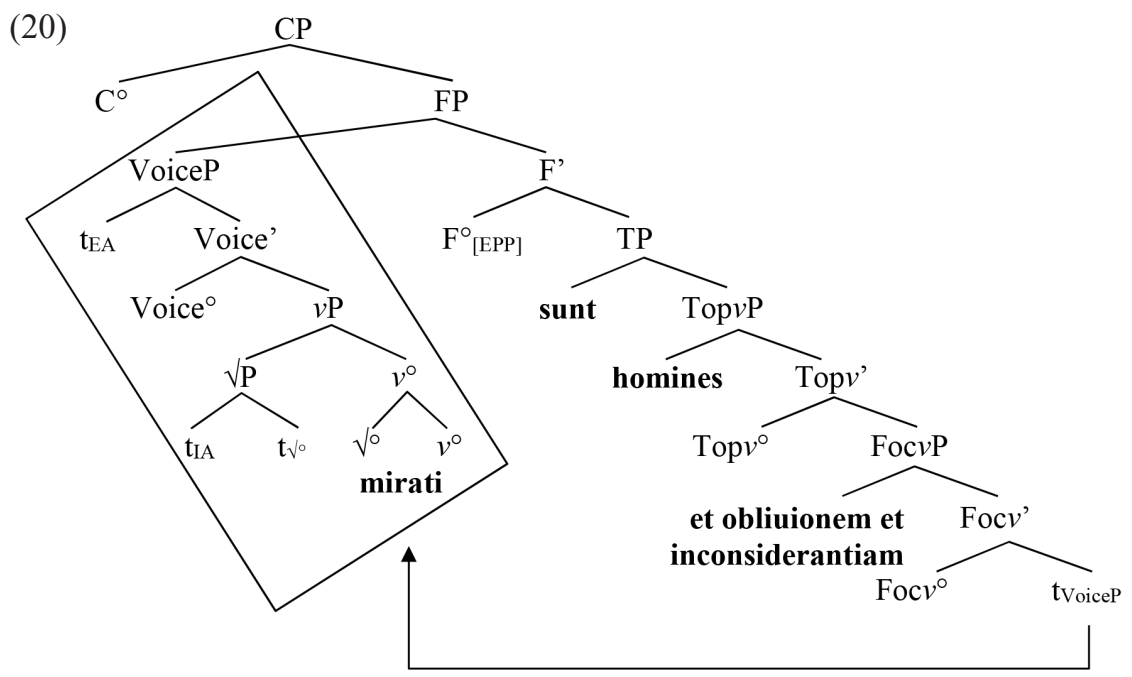

Three tentative conclusions can be drawn at this point. First, short topicalization and/or focalization to the low left periphery may well have been available in Latin. Second, given the relative scarcity of the orders VAuxSO (and VAuxOS) (cf. Table 1 in the next section), it seems to be the case that the relevant operations were only optional, and that genuine VP-internal subjects were possible (for example in clauses featuring the word order ' $\mathrm{C}$ - (manner) adverb - SOVAux'). Third, in all likelihood short topicalization and focalization were possible in AuxVP-clauses too, but given that AuxVP-sequences generated by Grammar A are always very difficult to distinguish from surface-identical strings generated by Grammar B, it would be difficult to draw strong conclusions from clauses featuring the word orders 'AuxVSO' and 'AuxVOS', which in Grammar A would involve movement of the auxiliary to G).

\subsection{VAuxOS and VAuxSO in Grammar B}

This brings us to an additional question: is an analysis of VAuxSO and VAuxOSclauses in terms of short topicalization/focalization possible in a Grammar B setting too? Assuming the structure detailed in (13) (VPAux) and (14) (AuxVP), the answer would have to be that although movement to Foc $v \mathrm{P}$ and Top $v \mathrm{P}$ is presumably available in both both types of clauses in Grammar B, only in AuxVP-clauses would short focalization or topicalization be able to yield a linear AuxVP order. Consider why this is so.

Recall that the main empirical motivation for assuming the structure in (13) for VPAux-clauses in Grammar B is the scarcity of the word order pattern 'VOAux' after 250 AD. More precisely, in this grammar VPAux-orders are not derived through VP movement, and as a result, the type of stranding analysis sketched in (20) is not available in this grammar (pace Jayaseelan 2010). Assuming that 
rightward specifiers are in general not available, we would have to conclude that in Grammar B, there can be no VAuxXP-clauses in which XP sits in Top vP or Foc $v \mathrm{P} .{ }^{17}$ One would then predict these word orders to be less well attested in later centuries than in earlier ones. However, as shown in Table 2, this is not the case, as both patterns are in fact more frequently attested in the last four centuries in my corpus (i.e. in the stage where Grammar B is the predominant one), both in absolute and in relative terms. ${ }^{18}$

The key to understanding this unexpected state of affairs is given in Table 3. As it turns out, the overwhelming majority of the Late Latin VAuxOS and VAuxSOorders occur in clauses with a deponent BE-periphrasis, whereas the figures for clauses with a modal verb are very low in Late Latin too (but note that the order 'infinitive - modal' is comparatively rare in this period). Interestingly, of the 53 Late Latin VAuxOS/VAuxSO-clauses, 38 (17 VAuxOS, 21 VAuxSO) come from one body of texts, viz. samples of the Latin Bible, where Grammar B is very strongly represented (witness for instance the quasi-absence of VOAux-orders).

I would like to interpret these data as follows. As discussed in Danckaert (2016, 2017a,b), Late Latin texts display surprisingly high frequencies of headfinal BE-periphrases, which are attested in more than $80 \%$ of the cases. On the other hand, in the same texts the head-initial 'modal - infinitive' orders tends to outnumber head-final ('infinitive - modal') structures. Given later developments in Romance (where head-initial syntax is the norm), the behaviour of BE-

Table 2. Frequency of the word orders 'VAuxOS' and 'VAuxSO' over time

\begin{tabular}{lcc}
\hline & Early (200 BC - 200 AD) & Late (201 - 600 AD) \\
\hline VAuxOS & 13 & 27 \\
VAuxSO & 14 & 33 \\
\hline Total \# of VPAux-clauses & 1064 & 511 \\
\hline
\end{tabular}

Table 3. Frequency of the word orders 'VAuxSO' and 'VAuxOS': modals and BE-auxiliaries compared

\begin{tabular}{lcccc}
\hline & \multicolumn{2}{c}{ Early $(200 \mathrm{BC}-\mathbf{2 0 0}$ AD) } & \multicolumn{2}{c}{ Late $(201-600$ AD $)$} \\
\cline { 2 - 5 } & BE & modal & BE & modal \\
\hline VAuxOS & 9 & 4 & 23 & 4 \\
VAuxSO & 12 & 2 & 30 & 3 \\
\hline Total \# of VPAux-clauses & 392 & 672 & 276 & 235 \\
\hline
\end{tabular}

17. Recall also that I take multiple extraposition of argument DPs not to be available.

18. Note that I am not using the term 'early' as in 'Early Latin' (i.e. the language used in Latin texts dating from ca. 250-150 BC). 
periphrases is of course unexpected. In Danckaert (2016), it was proposed that this state of affairs is related to the prosodically weak status of (monosyllabic) forms of Late Latin non-copular BE. In particular, 'weak BE' is argued to correspond to a (monosyllabic) foot which cannot project an independent phonological word. Such a 'stray foot' can only survive in a given syntactic configuration if it is linearized at the right edge of a phonological phrase, where it counts as extrametrical (say 'invisible at PF'). This is the case whenever this element appears in an absolute clause-final position, and when a ' $\mathrm{PaPa}$ - $\mathrm{BE}$ ' sequence is only followed by one or more extraposed constituents (one of which could in principle be the subject or the object).

Critically, the only context in which 'weak BE' can survive in a given representation without appearing at the end of a phonological phrase is one in which it forms a complex head with another $\mathrm{X}^{\circ}$-category. This happens for instance in negated clauses, which is the one environment in which Late Latin BE-periphrases are productively head-initial (see Danckaert 2016, 2017a: chapter 6). In a nutshell, the logic of this argument is that in the case of complex head formation (which I take to involve syntactic head-to-head movement), weak BE is part of a unit (an $\mathrm{X}^{\circ}$-constituent) which at spell-out is automatically mapped onto a prosodic word (because it is simply too heavy not to constitute a p-word of its own). As a result, there is no need for BE-auxiliaries in negated contexts to appear in an extrametrical position (i.e. at the end of a p-phrase). I refer to Danckaert (2016) for the full story.

Returning then to Late Latin VAuxSO and VAuxOS-clauses with a BE-auxiliary such as (21), I would like to propose that these involve a process of complex head formation too, namely incorporation of the lexical verb into the head hosting the auxiliary. This goes against what is suggested in Danckaert (2017b: 231233), where it is argued that Late Latin ' $\mathrm{PaPa}$ - Aux' sequences do not involve $\mathrm{V}$-incorporation. Evidence for this claim comes from word order in negated clauses with a head-final BE-periphrasis (which as we have seen are the minority pattern in Late Latin, the statistically predominant order being 'Neg-BE-PaPa'). Danckaert (2017b) observes that in VPAux-clauses, the order 'V-Neg-BE' persists, and concomitantly, that the order 'Neg-V-BE' is (which would be compatible with a $\mathrm{V}$-incorporation account) is relatively poorly attested. However, in Danckaert (2017b) no material from the Vulgate was taken into account, which is the only body of texts in which the orders 'VAuxSO' and 'VAuxOS' are really productive (and where in negated clauses with a BE-periphrasis we almost exclusively find 'Neg-BE-PaPa' orders). What I would like to propose is that $\mathrm{V}$-incorporation was in fact available, but not for every speaker, and therefore that there are no traces of it in all Late Latin texts. This would go some way to explain why the attested 'PaPa-BE-OS' and 'PaPa-BE-SO' orders in my corpus are so unevenly distributed over the various Late Latin texts (recall that the bulk examples comes from one and the same text, viz. the Vulgate).

If this 'optional incorporation' analysis is on the right track, the structure of an example like (21) could then for instance be as in (22) (where I simply represent the conjunction quia 'because' in $\mathrm{C}^{\circ}$ ): 
(21) quia consolat-us est Domin-us popul-um su-um because consoled-NOM.M.SG be.PRS.3SG Lord-NOM people-ACC his-ACC 'because the Lord has comforted his people' (Vulg. VT Is. 49.13)

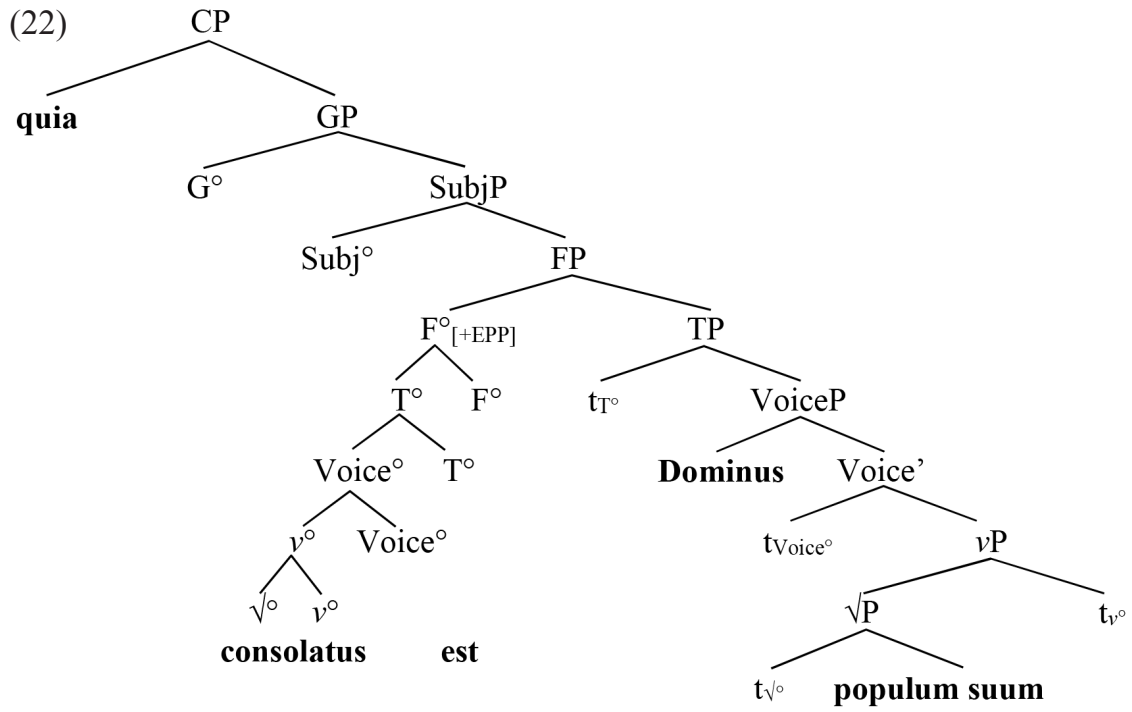

As can be observed, this structure does not involve a head-final TP, but rather it is an AuxVP-clause in which the lexical verb first left-adjoins to T, and in which the complex head thus formed moves on to F (as dictated by the rules of Grammar B). In (22), the subject is represented in its thematic base position, but nothing precludes an analysis according to which it has undergone movement to a low topic or focus projection. In addition, as we will see in section 5.2, it is actually conceivable that the subject has undergone A-movement to SubjP (not represented in (22)), and that the surface effect of this operation is masked by subsequent verb movement to the higher verb position $\mathrm{G}$ discussed in section 2 . In the absence of adverbial material that could disambiguate the exact position of the verb forms in an example like (21), the position of the subject would itself also be ambiguous between a VP-internal and a TP-internal parse.

\subsection{To sum up}

In this section I have suggested that there are two different patterns of VP-internal subject placement, (a) one where a (presumably discourse-neutral) subject occurs in its thematic base position, and (b) one where it has undergone short movement to a low topic or focus projection. In what follows, I will not make any further distinction between these two types of VP-internal subject placement, as they can both be considered to be neither left or right-peripheral, nor A-moved. In addition, we have also seen that especially in Late Latin certain 'PaPa-BE(-XP)'-patterns 
are ambiguous between a number of possible parses, including a pattern in which the lexical verb is incorporated in the auxiliary, a possibility which I take not to be available in clauses with a modal verb.

In the next section I will introduce the details of an approach to syntactic change which makes crucial reference to the potential for linguistic utterances to be structurally ambiguous, and to the way in which structural ambiguity is dealt with by the language learner.

\section{The 'variationist acquisition' approach to language change (Yang 2000, 2002a,b)}

As hinted at earlier, I am assuming a grammar competition approach to language variation and change (Kroch 1989, 1994). In the case at hand, this approach entails that speakers of Latin had access to both Grammar A and Grammar B, perhaps throughout the entire period under discussion (viz. $200 \mathrm{BC}-600 \mathrm{AD}$, cf. section 6.1). Variation resides in the frequencies at which these two pairs of competing grammars were employed. In addition, it is conceivable that these different grammars were associated with different conditions of usage, although it has to be added that that there are at present very few (if any) reliable (and methodologically sound) empirical studies of this type of synchronic variation in Latin.

Yang $(2000,2002 a, b)$ provides a probabilistic algorithm to model the dynamics of two or more competing grammars, and to determine how successful a grammar is in parsing the data a language acquiring child is exposed to. One important aspect of his approach is the (among generative linguists very common) assumption that language change is a discontinuous process, whereby a language acquiring child reanalyses (part of) the data that she is exposed to during the critical period, in the sense that she assigns a phrase structure analysis to a given surface string in the Primary Linguistic Data (PLD) which is different from the representation assumed by the speaker who produces the relevant utterance. Yang argues that each grammar $\mathrm{G}$ a child has access to is associated with a probabilistic weight, i.e. the probability that the child will use $\mathrm{G}$ and not any competing grammar to parse a given utterance. More precisely, each time a child chooses grammar $\mathrm{G}_{1}$ and successfully parses a sentence from the PLD (Primary Linguistic Data), the weight of $\mathrm{G}_{1}$ increases, and the weight of the competitor $\mathrm{G}_{2}$ decreases.

Assuming a two-way competition between a grammar $\mathrm{G}_{1}$ and a grammar $\mathrm{G}_{2}$, we can distinguish three types of clauses in the PLD: (i) clauses that can only be generated by $\mathrm{G}_{1}$, (ii) clauses that can only be generated by $\mathrm{G}_{2}$ and (iii) clauses that are structurally ambiguous in that both grammars $G_{1}$ and $G_{2}$ can generate them. The fitness of $G_{1}$ is then defined as the proportion of clauses in the PLD that can only be generated by $\mathrm{G}_{1}$. Finally, we can characterize the advantage of $\mathrm{G}_{1}$ over its competitor $\mathrm{G}_{2}$ as the fitness of $\mathrm{G}_{1}$ minus the fitness of $\mathrm{G}_{2}$. Yang's model predicts that in the long run, the fittest grammar wins out, unless independent factors bring about a change through which the relative fitness of $\mathrm{G}_{1}$ and $\mathrm{G}_{2}$ changes.

Before we can apply this theoretical machinery to Latin corpus data to assess the fitness of the two hypothesized grammars which are the main focus of the pres- 
ent paper, viz. the grammar with and the one without A-movement for subjects, we first have to spell out precisely under which conditions we can be certain that we are dealing with a VP-internal and a TP-internal subject in Latin, which is what I will do in the following section.

\section{Cues for VP-internal and TP-internal subjects}

\subsection{Distinguishing 'peripheral' from 'clause-internal' subjects}

I will start by discussing environments in which a subject XP is or can be located in a peripheral position, which I will loosely define as any position in the clause which is structurally higher than SubjP. Peripheral subjects can be linearized either to the left or to the right of the main body of the clause. The reason why clauses containing a peripheral subject do not inform us about the presence or absence of A-movement is of course that it cannot be assessed whether a given subject was moved to a peripheral position directly from within the VP or rather via an intermediate step in the TP-layer.

\subsubsection{Left-peripheral subjects}

As was mentioned in section 3.1, subordinating conjunctions and fronted $w h$-items of various kinds are the most reliable diagnostic to tell whether a given constituent is left-peripheral or not. Consider for instance the minimal pair in (23)-(24) (where the label 'TP' is used as shorthand for the entire articulated middle field). Both examples feature an adverbial clause introduced by cum 'when', and in both cases the subject is the proper name Scipio. In the first example, this element appears to the left of cum, and in the second example it appears to its right:

(23) Ceterum [FocP Scipio [FinP cum [TP conloqui-um haud abnu-isse-t]]], furthermore Scipio.NOM when meeting-ACC not refuse-PLPFV.SBJV-3SG amb-o ex composit-o duc-es castr-a both-NOM.M.PL from pre-arrangement-ABL generals-NOM camp-ACC protul-erunt $\quad[\ldots]$. move.forwards-PRF.3PL

'Furthermore, when Scipio had approved of the meeting, both generals concertedly moved forward their camps.' (Liv. 30.29.8)

(24)

$$
\begin{aligned}
& {\left[\begin{array}{llll}
\text { FinP } & \frac{\text { Cum }}{\text { when }} & {\left[_{\text {TP }} \begin{array}{l}
\text { Scipio } \\
\text { Scipio.NOM nothing.ACC }
\end{array}\right.} & \text { be.lacking-PTCP.FUT-ACC.N.SG }
\end{array}\right.} \\
& \text { iis profecto dic-ere-t]], tum rursus mulier: }[\ldots] \text {. } \\
& \text { this.DAT.F.PL surely say-IPFV.SBJV-3SG then again woman.NOM }
\end{aligned}
$$

'When Scipio said that they would certainly lack nothing, then the woman said: ...' (Liv. 26.49.12)

As mentioned in Danckaert (2012: 4-6), there is every reason to assume that what is variable in this minimal pair is subject placement, and that the position of 
the conjunction cum remains constant. We can assume that the latter sits in a low left-peripheral position, say FinP. It follows that we can be sure that the subject in (23) has been moved to the left periphery, and that it sits somewhere below FinP in (24). In the corpus study that I will report on in section 6, all unambiguously left-peripheral subjects (or direct objects) of this type were excluded (and thus not even taken up in the set of ambiguous clauses). In addition, we also know that - at least in prose texts - the hierarchically highest verb of a clause (very often a finite verb) never occurs to the left of $w h$-words and complementizer-like elements (cf. Danckaert 2012: 275), from which we may deduce that in Latin the highest verb cannot move to the CP-layer, at least not past Fin. By transitivity, we can be confident that any element below an auxiliary (which is almost always the highest verb in its clause) is itself also non-left-peripheral. Finally, all subjects which are not preceded by an auxiliary and/or a C-element are either left-peripheral, or located somewhere below Fin. All this is summarized in (25) (where \# designates the left and right edges of a clause, and where angle brackets indicate that the presence of additional material is only optional):

$$
\begin{array}{cccc}
\text { (25) a. \# } \mathrm{S} & \mathrm{C} & \ldots & \# \mathrm{~S}=\text { unambiguously left-peripheral } \\
\text { b. } \# \mathrm{C} & \mathrm{S} & <\ldots>\# \mathrm{~S}=\text { unambiguously non-left-peripheral } \\
\text { c. } \# \text { Aux } & \mathrm{S} & <\ldots>\# \mathrm{~S}=\text { unambiguously non-left-peripheral } \\
\text { d. } \#<\ldots> & \mathrm{S} & <\ldots>\# \text { position of } \mathrm{S}=\text { ambiguous (in CP, TP or VP) }
\end{array}
$$

\subsubsection{Right-peripheral (extraposed) subjects}

Distinguishing clause-internal from right-peripheral constituents in Latin is slightly more difficult. ${ }^{19}$ As mentioned in section 3, I will assume that the phenomenon of extraposition either involves rightward movement and adjunction to some high functional category, or left-peripheral fronting of a focalized constituent followed by remnant movement (without taking a stance as to which analysis is correct, or whether we need both). In the same section it was also pointed out that multiple argument extraposition within one and the same clause does not seem to be available. Formulating this generalization slightly more accurately one could say that an extraposed subject or direct object has to occur at the absolute end of a clause, from which it follows that argument extraposition cannot be iterated. Let us have a look at some data that corroborate this point. For instance, Modern French has a process of subject inversion which is called 'focus inversion' in Lahousse (2006) (which is to be distinguished from 'genuine' (i.e. VP-internal) inversion). As shown in (26), in cases of focus inversion a subject must appear at the right edge of the clause (data from Lahousse 2006: 426, 453): 
(26) a. Pass-er-a [ ${ }_{\mathrm{PP}}$ devant le conseil de discipline] $\left[_{\mathrm{DP}}\right.$ tout élève de go-FUT-3SG before the committee of discipline every pupil of l' établissement au comportement incivil]. the institution with.the behaviour inappropriate.

'Every pupil of the school with inappropriate behaviour will appear before the disciplinary committee.'

b. *Passera $\left[_{\mathrm{DP}}\right.$ tout élève de l'établissement au comportement incivil] [ ${ }_{\mathrm{PP}}$ devant le conseil de discipline].

Similarly, in English a direct object that has undergone Heavy NP Shift cannot be followed by any clause-mate constituent. To the extent that the pattern in (27b) is acceptable at all (speakers' judgments tend to vary in this respect), the clause-final adjunct last Monday has to be right-dislocated and mapped onto an independent intonational unit, suggesting that it is not properly integrated in the same clause as the shifted object my rich uncle from New York:

(27) a. I met [ ${ }_{\mathrm{PP}}$ on the street] [ ${ }_{\mathrm{DP}}$ last Monday] [ ${ }_{\mathrm{DP}}$ my rich uncle from New York].

b. \% I met $\left[_{\mathrm{PP}}\right.$ on the street] $\left[_{\mathrm{DP}}\right.$ my rich uncle from New York] [DP last Monday].

What I will do to exclude as many potentially extraposed subject XPs as possible is classify as 'structurally ambiguous' all (VPAux and AuxVP-)clauses (i) in which the subject occurs in an absolute clause-final position, or (ii) where the subject is only followed by a constituent which is likely not to be fully integrated in the same clause, such as an adverbial clause. As I will discuss at the end of the following section, some postverbal subjects in AuxVP-clauses which are followed by at least one clause-mate constituent will be classified as 'unambiguously VP-internal'.

Let us then turn to the way in which VP-internal subjects can be identified.

\subsection{Unambiguous evidence for VP-internal subjects}

As a first approximation, we can say that a given subject XP is unambiguously VP-internal if it occurs to the right of an element which demarcates the boundary between the VP and the TP-layer. (Various kinds of) adverbs and the lexical verb itself are the most reliable such demarcating categories, but crucially only when these elements themselves do not occur in a peripheral position.

Following the same logic as in section 5.1.1 where we discussed left-peripheral subjects, whether or not a given adverbial expression is left-peripheral can be assessed in clauses featuring an element which itself is unambiguously left-peripheral, such as adverbial subordinators and relative or interrogative wh-phrases. As mentioned earlier, fronted foci typically occur to the left of such elements. In the case of a focus-fronted adverb, such as the manner adverbs bene 'well' and male 'badly' in (28), this yields the order 'adverb - subordinator/wh-phrase': 
(28) Et scrib-a-s mihi ueli-m de gladiator-ibus, and write-PRS.SBJV-2SG me.DAT want.PRS.SBJV-1SG about gladiators-DAT sed ita [bene [si re-m ger-unt]]; but so good.ADV if matter-ACC do-PRS.3PL non quaer-o [mal-e [si se gess-erunt]]. not ask-PRS.1SG bad-ADV if REFL.ACC do-PRF.3PL

'And I would like you to write me about the gladiators, but only if they behave properly; if they behave badly, I'm not interested.' (Cic. Att. 4.8.2)

On the other hand, whenever an adverb occurs to the right of a low left-peripheral item, we can be confident that it occurs in its base position, assuming that the ordering of adverbial modifiers in the extended VP and TP is completely rigid (Cinque 1999). We also know that SubjP is located fairly high in the TP-layer: let us assume that any subject below a non-left-peripheral adverb should be VP-internal (type 'C-Adv-S-[...]', where 'C' stands for any category that somehow demarcates the lower edge of the CP-layer, for example a subordinator, but also an auxiliary). This conclusion holds for both VPAux and AuxVP-clauses. As the reader can verify, examples (17) and (18) are cases in which a subject XP can be identified as VP-internal by virtue of appearing to the right of an unambiguously non-left-peripheral (manner) adverb.

Turning to the status of auxiliaries as clues for structural disambiguation, it is important to point out that in a Grammar B setting, not all clauses featuring the order 'AuxSV' involve a VP-internal subject. As we have seen in section 2, finite verbs can occur in (at least) two positions. Recall that there is good evidence that the higher of these two verb positions is itself higher than SubjP: as a result, AuxSV-clauses which do not feature any adverbial material are ambiguous between the three types of structures given in (29). In (29a), the auxiliary sits in F and the subject remains low, whereas in the string-identical structure in (29b), the auxiliary raises to $\mathrm{G}$ across an A-moved subject in SpecSubjP. In (29c), verb movement to $\mathrm{G}$ occurs in a clause with an in situ subject:

(29) a. $\left[_{\text {SubjP }}\left[\left[_{F P} \operatorname{Aux}\left[{ }_{T P} t_{\text {Aux }}\left[{ }_{V o i c e P} \mathbf{S}\left[{ }_{\text {Voice' }},\left[{ }_{\nu P} \mathbf{V}\left[{ }_{\sqrt{P}} t_{V}\right]\right]\right]\right]\right]\right]\right.\right.$

b. $\left[_{G P} \operatorname{Aux}\left[_{\text {SubjP }} \mathbf{S}\left[_{\text {Subj' }}\left[_{F P} t^{\prime}{ }_{\text {Aux }}\left[{ }_{T P} t_{\text {Aux }}\left[{ }_{V \text { oiceP }} t_{S}\left[{ }_{V o i c e},{ }_{v P} \mathbf{V}\left[{ }_{\sqrt{P}} t_{V}\right]\right]\right]\right]\right]\right]\right]\right]$

c. $\left[_{\mathrm{GP}} \operatorname{Aux}\left[_{\text {SubjP }}\left[\left[_{\mathrm{FP}} \mathrm{t}^{\prime}\right.\right.\right.\right.$ Aux $\left.\left.\left.\left[{ }_{\mathrm{TP}} \mathrm{t}_{\text {Aux }}\left[{ }_{\text {VoiceP }} \mathbf{S}\left[_{\text {Voice }},\left[_{v \mathrm{P}} \mathbf{V}\left[{ }_{\sqrt{\mathrm{P}}} \mathrm{t}_{\mathrm{V}}\right]\right]\right]\right]\right]\right]\right]\right]$

It should be clear that only auxiliaries in the lower verb position can be used to identify VP-internal subjects. In order to distinguish the two types of AuxVPclauses discussed in section 2 we once again need evidence from adverb placement. Recall that one can use aspectual and modal adverbs as a diagnostic to assess whether or not a given finite verb occurs in its base position. I will assume that aspectual and modal adverbs occur above TP and FP, and below SubjP and GP (compare the representation in (12) and the discussion at the end of section 2.3.2). Given all this, we can conclude that the one context in which a VP-internal subject 
can unambiguously be identified as such is as the one sketched in (30) (where 'Adv' is a modal or aspectual adverb):

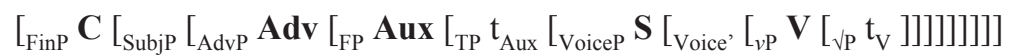

In this structure, the auxiliary can only occur in F, given that it follows an unambiguously non-left-peripheral adverb. As a result, the language learner can be confident that the subject has not been displaced to SubjP but rather sits inside the verb phrase. In any event, the pattern in (30) is only a special case of the broader category of 'C-Adv-S-[...]' contexts in which we can be sure that we are dealing with a VP-internal subject.

Let us then look at cases where a non-peripheral subject occurs to the right of the lexical verb. I shall consider 'VP-internal' all cases where the subject occurs to the right of the lexical verb, and where it is followed by either the auxiliary or at least one XP which is not an adverbial clause but rather a DP, PP or adverb which we can take to be fully integrated in the same clause as the subject we are interested in (along the lines discussed in the previous section). In other words, included in this category are all clauses featuring the word orders 'VSAux' and 'AuxVS-XP' (more generally 'V-S-[...]'). An example of the latter category is given in (31), where the pronominal subject ipse 'he (himself)' occurs after an auxiliary, a lexical verb and a direct object, but still to the left of the indirect object Diodoro 'from Diodorus':

quia non pot-uera-t $\quad$ erip-ere $\quad$ argent-um ips-e
because not be.able-PLUPRF-3SG take.away-PRS.INF silver-ACC self-NOM
Diodor-o
Diodorus-DAT
'because he himself had not been able to take away the silver from Diodorus'
(Cic. Ver. 4.39)

Alhough it very much remains to be seen how and why a non-finite lexical verb can end up to the left of an external argument ${ }^{20}$, I take it that we can be reasonably confident that in the patterns mentioned we are dealing with a VP-internal subject.

Finally, there are two additional classes of word order patterns which we can take to involve a VP-internal subject. First, as discussed in section 3, certain types of VAuxSO-clauses might involve a subject that has undergone short topicalization or focalization to the VP-edge. Assuming that an alternative analysis of this type of word order pattern involving $\mathrm{V}$-incorporation is only available for clauses with a BE-auxiliary, I will take it that all (and only) clauses featuring the order 'Inf-modal-S-XP' feature a VP-internal subject, whereas VAuxSO-clauses with a BE-periphrasis are in principle ambiguous between the two analyses sketched in sections 3.1 and 3.2 .

20. On the (limited) availability of TP-internal movement of a non-finite remnant verb phrase, see Danckaert (2017a: 199-209). 
Second, recall from section 2.2 that in Danckaert (2017a) the original empirical motivation to distinguish Grammar A from Grammar B was the decline of the order 'VOAux'. Given the theoretical assumptions on EPP-checking spelled out earlier, one would be forced to classify all (unambiguously non-left-peripheral) clauses featuring the order 'SVOAux' as involving a VP-internal subject, as by assumption Grammar A (which is the only grammar that can generate VOAux-orders) does not have A-movement for subjects. Needless to add, this type of reasoning contains some unwanted circularity: as presence or absence of A-movement is what we want to uncover, it would hardly be fair to build it into our set of assumptions. Fortunately however, as will be shown in section 6, whether or not we classify all subjects in 'C-[...]-SVOAux'-clauses as VP-internal does not fundamentally alter our results.

\subsection{Unambiguous evidence for TP-internal subjects}

Moving on to TP-internal subjects, it should come as no surprise that here too we can use functional material such as adverbs, subordinators, and now also auxiliaries, as diagnostics to disambiguate various word order patterns. The simplest case where we can be confident that a given subject XP sits in an A-position involves AuxVP-clauses where a subject occurs to the left of an auxiliary, but to the right of a C-element: in other words, all ' $\mathbf{C}-\mathbf{S}-\mathbf{A u x}-\mathbf{V}$ '-sequences can be taken to involve an A-moved subject.

In addition, it is also possible that a subject occurring lower than an auxiliary has undergone A-movement. We can be sure that this is the case whenever it occurs to the left of an adverb. In such cases, the auxiliary must have undergone movement to the higher verb position $\mathrm{G}$. The structure we thus obtain is detailed in (32); (33) is a corpus example where this pattern is instantiated (compare also (15) in section 2.3.2):

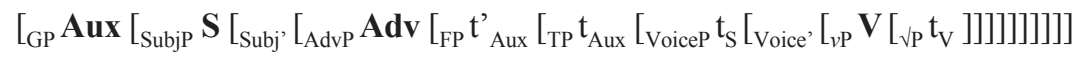

$$
\begin{aligned}
& {\left[_ { \mathrm { GP } } \text { Pot-est etiam } \left[_{\text {SubjP }} \text { inlitterat-us } \text { }_{\mathrm{i}},[[\text { dum modo }\right.\right.} \\
& \text { be.able-PRS.3SG even illiterate-NOM while only } \\
& \text { tenac-issim-ae memori-ae }],\left[_ { S c r P } \text { re- } m _ { j } \left[_{\text {AdvP }}\right.\right. \text { satis commod-e } \\
& \text { tenacious-SUP-GEN memory-GEN matter-ACC enough convenient-ADV } \\
& \text { [VoiceP } \mathrm{t}_{\mathrm{i}} \mathrm{t}_{\mathrm{j}} \text { administra-re ]]]]]]. } \\
& \text { manage-PRS.INF }
\end{aligned}
$$

'Even an illiterate person can cope with the matter sufficiently well, as long as he has a flawless memory.' (Col. 1.8.4)

Similarly, in VPAux-clauses too subjects in SubjP can unambiguously be identified whenever we find the string 'C-S-Adv'. The structure looks as in (34), and an example is given in (35):

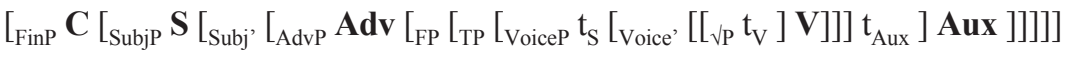


(35)

$\begin{array}{llllll}\text { quin se } & \text { [ill-e } & \text { Marcell-us } & \text { tant-us uir] } & \text { sic } \\ \text { that } & \text { REFL.ACC } & \text { that-NOM.M.SG } & \text { Marcellus-NOM } & \text { such-NOM man.NOM } & \text { so }\end{array}$

[ad tolera-nd-um aequ-o anim-o exili-um] saepe

to bear-GDV-ACC.N.SG equal-ABL mind-ABL exile-ACC often

adhortat-us si-t: $\quad[\ldots]$.

encouraged-NOM.M.SG be.PRS.SBJV-3SG

'that the great man Marcellus often encouraged himself in this manner, in order to bear his exile with a calm mind' (Sen. Dial. 12.9.7)

\subsection{Summary}

To sum up, I have suggested that we can be confident that we are dealing with a VP-internal subject whenever we find the patterns (i) 'C-Adv-S-[...]', (ii) 'VS[...]', (iii) 'Inf-modal-S-XP', or (iv) 'C-SVOAux'. On the other hand, I take it that all clauses featuring the patterns (i) ' $\mathrm{C}-\mathrm{S}-\mathrm{Aux}-\mathrm{V}-[\ldots]$ ' or (ii) 'C-S-Adv-[...]' containing a subject that has undergone A-movement, which by hypothesis is only an available option in Grammar B. All subject XPs which do not occur in one of these environments should be considered structurally ambiguous and uninformative for the language learner when it comes to deciding whether a given utterance was generated by the grammar that allows for A-movement or the one that doesn't.

\section{Subject placement in Classical and Late Latin: the corpus evidence}

\subsection{Methodology}

In order to test the hypothesis spelled out at the end of section 2.4, according to which there is a pair of competing grammars with and without (obligatory) A-movement for subjects, I will look at corpus evidence to assess how robustly TP-internal subjects are cued over time, thereby concentrating on external arguments (and thus not on subjects in passive/unaccusative contexts).

The text corpus used is the same as in Danckaert (2017a): it contains 39 text samples from ca. 200 BC (Plautus) until the late sixth century AD (Gregory of Tours). Texts were either drawn from the LASLA-corpus (http://cip193.philo.ulg. ac.be/OperaLatina) or from the Brepolis database (http://www.brepolis.net). Full details can be found in Danckaert (2017a: 83-87). From this text corpus I collected a total of 2473 clauses containing (i) a non-finite transitive verb (past participle or infinitive), (ii) an auxiliary (BE in combination with a deponent participle, or a modal verb (possum 'be able' or debeo 'have to') ${ }^{21}$, (iii) a non-clausal overt subject

21. Recall however that the presence of an auxiliary (functional verb) is sometimes, but definitely not always necessary to determine the exact position of a given subject XP: in particular, the orders 'C-Adv-S-[...]' and 'C-S-Adv-[...]' represent unambiguous evidence for VP-internal and TP-internal subjects respectively, without reference being made to verb forms of any kind. As a result, given that the present corpus study is only based on clauses which do in fact feature an auxiliary, it would be interesting to perform a follow-up study where subject placement is evaluated in a wider range of environments (i.e. where clauses with a single synthetic verb are also taken into account.). 
and (iv) an overt direct object. The reason why only clauses with an overt direct object were taken into account is that this allows us to be maximally confident that we are dealing with a true agentive subject (external argument). No clauses with a clausal direct object and/or subject were taken up in the sample, nor were clauses with an overt but unambiguously left-peripheral subject or object.

The dataset used for this study, as well as a separate file with the R-code used to extract the quantitative data summarized in Tables 2-5 are available online at the following url: $<$ https://opendata.uit.no/dataset.xhtml?persistentId=doi\%3A10. 18710\%2FV9D674>.

\subsection{Results}

Let us then move on to the results of the corpus study. To assess the diachrony of subject placement in the history of Latin, I will compare the fitness of the hypothesized [+ A-movement] and [- A-movement] grammar in the first half of the corpus (200 BC - 200 AD, 1577 clauses) with the corresponding figures in the second half of the corpus (201 - 600 AD, 896 clauses). The figures are given in Table 4: for both periods, I give the total amount of clauses in three conditions, namely (i) unambiguously VP-internal subjects, (ii) unambiguously TP-internal subjects and (iii) ambiguous clauses. I also provide figures for each of the unambiguous environments identified in section 5 .

Given these results, the fitness of the [- A-movement] grammar in the earlier period would be $.1475(185 / 1254)$, whereas the [+ A-movement] grammar clocks off at .1100 (viz. 138 unambiguous tokens out of a total of 1254). It is especially the high frequency of postverbal (but non-clause-final) subjects that seems to give an edge to the [- A-movement] grammar. The advantage of this grammar can be estimated to be .0375 . Importantly, we can be confident that the fact that we observe 185 VP-internal subjects out of a total of 323 unambiguous tokens is not due to chance (Pearson's chi-squared test, $\mathrm{p}=.001449715$ ). Recall that one potentially problematic element of the design of this study is the decision to classify all

Table 4. Assessing the fitness of the [- A-movement] and the [+ A-movement] grammar

\begin{tabular}{|c|c|c|c|c|c|}
\hline \multicolumn{3}{|c|}{ Early (200 BC - 200 AD) } & \multicolumn{3}{|c|}{ Late (201 - 600 AD) } \\
\hline \multirow[t]{5}{*}{ VP-internal } & C-Adv-S-[...] & 15 & \multirow[t]{5}{*}{ VP-internal } & C-Adv-S-[...] & 3 \\
\hline & VS-[...] & 135 & & VS-[...] & 23 \\
\hline & Inf-modal-S-XP & 3 & & Inf-modal-S-XP & 4 \\
\hline & C-SVOAux & 32 & & C-SVOAux & 8 \\
\hline & Total & 185 & & Total & 38 \\
\hline \multirow[t]{3}{*}{ TP-internal } & C-S-Adv-[...] & 16 & \multirow[t]{3}{*}{ TP-internal } & C-S-Adv-[...] & 7 \\
\hline & C-S-Aux-V-[...] & 122 & & C-S-Aux-V-[...] & 91 \\
\hline & Total & 138 & & Total & 98 \\
\hline Ambiguous & & 1254 & Ambiguous & & 760 \\
\hline
\end{tabular}


'C-SVOAux'-clauses as generated by Grammar A, and by this token as involving a VP-internal subject. However, even if we were to classify all early tokens of a subject XP occurring in an 'C-SVOAux'-clause as ambiguous, we still obtain a significant result, as the probability of obtaining 153 out of a total of 291 clauses is also statistically significant at the .05 level $(\mathrm{p}=.03178521)$.

In the later period on the other hand, the roles are reversed. Here the fitness of the [- A-movement] grammar drops to $.05(38 / 760)$, whereas the fitness of the [+ A-movement] grammar rises to .1289 (98/760). This difference too is statistically significant, as it is highly unlikely for TP-internal subjects to outnumber VP-internal ones by 98 to 38 if the distribution of these two patterns were governed by chance $(\mathrm{p}<.000001)$.

\subsection{Discussion}

The data summarized in Table 4 clearly show that the distribution of VP and TP-internal subjects does not remain constant over time; rather, in later centuries A-movement to the TP-layer clearly is more prevalent ('fitter') than in earlier times. As hinted at in section 2.4, it is probably not the case that this particular instance of grammar competition leads to a scenario in which the latter grammar completely ousts the former, as in most (if not all) present day Romance languages both VP and TP-internal subjects are still part of the grammar (with the privoso that the VP-internal pattern is most readily available with one-place (unaccusative and unergative) predicates). Instead, it seems to be the case that both grammars are retained, in such a way that they are not (or cease to be?) interpretively equivalent. This is in line with the well known generalization that the alternation between preverbal and postverbal subjects in present day Romance is conditioned by among other things information structure (a factor which however does not play exactly the same role in all Romance varieties). Again, further research is needed to verify whether this line of reasoning is on the right track.

An obvious question that arises at this point concerns the reason(s) why the [+ A-movement] grammar became more prominent over time. One factor that is likely to be related with this instance of syntactic change is an independent change which takes place in the same period, namely the shift towards an exclusively head-initial T-node. As shown in Table 5, in both the early (169 vs. 16) and the later period (26 vs. 12) TP-internal subjects are cued much more robustly in AuxVP than in VPAux-contexts.22

As documented in Danckaert (2017a: 220-222; 273), in clauses with a modal verb as well as in clauses with a perfective BE-auxiliary, the rate of the order 'AuxVP' clearly increases over time. The only environment in which the order 'VPAux' remains the majority pattern in Late Latin is (non-negated) BE-periphrases with a non-perfective auxiliary (see also section 3.2). As can be seen at the bottom

22. Both in the early and the late period, the differences between the frequencies of unambiguous VP-internal tokens observed in VPAux and AuxVP environments are indeed statistically significant (Pearson's chi-squared test; early: $\mathrm{p}<.0000001$; late: $\mathrm{p}=.009849737$ ). 
Table 5. Cueing subject placement in VPAux and AuxVP-clauses

\begin{tabular}{lcccc}
\hline & \multicolumn{2}{c}{ Early $(200 \mathrm{BC}-200 \mathrm{AD})$} & \multicolumn{2}{c}{ Late $(201-600 \mathrm{AD})$} \\
\cline { 2 - 5 } & VPAux & AuxVP & VPAux & AuxVP \\
\hline VP-internal & 169 & 16 & 26 & 12 \\
TP-internal & 13 & 125 & 3 & 95 \\
Ambiguous & 882 & 372 & 482 & 278 \\
Total & 1064 & 513 & 511 & 385 \\
\hline
\end{tabular}

row of Table 5, in absolute terms the order 'VPAux' retains a slight advantage over the reverse order in the last four centuries documented in the corpus (that is, when all types of auxiliaries are lumped together), but its predominance clearly isn't as strong any more as it once was. It is very tempting to hypothesize that the eventual shift to a generalized head-initial T-node has contributed to the fact that A-movement for subjects is available in all (present day) Romance varieties.

\section{Conclusion}

In this paper I have provided corpus data to document changing patterns of subject placement (VP-internal vs. TP-internal) in the history of Latin. Much of the discussion was centred around the question as to how VP-internal and TP-internal subject XPs can unambiguously be identified as such (by the ancient learner as well as by the modern syntactician). The results of my corpus study support the hypothesis that in the grammar which was most prevalent in the earliest stages of the Latin language, there was no rule of A-movement displacing subjects to the TP-layer, but rather, that this particular operation is an innovation which only becomes fully established in the Late Latin period. Finally, it was speculated that the shift to a head-initial T-node may have contributed to this development.

\section{References}

Alexiadou, Artemis \& Anagnostopoulou, Elena. 1998. Parametrizing AGR: word order, V-movement and EPP-checking. Natural Language and Linguistic Theory 16: 491-539. $<$ https://doi.org/10.1023/A:1006090432389>

Belletti, Adriana. 2001. "Inversion" as Focalization. In Hulk, Aafke \& Pollock, JeanYves (eds.). Subject Inversion in Romance and the Theory of Universal Grammar, 60-90. Oxford: Oxford University Press.

Belletti, Adriana. 2004. Aspects of the Low IP Area. In Rizzi, Luigi (ed.). The Structure of $C P$ and IP, 16-51. Oxford: Oxford University Press.

Biberauer, Theresa. 2003. Verb second (V2) in Afrikaans: A Minimalist Investigation of Word Order Variation. PhD dissertation, University of Cambridge.

Biberauer, Theresa \& Roberts, Ian. 2005. Changing EPP parameters in the history of English: accounting for variation and change. English Language and Linguistics 9: 5-46. $<$ https://doi.org/10.1017/S1360674305001528> 
Biberauer, Theresa \& Richards, Marc. 2006. True Optionality: when the Grammar doesn't mind. In Boeckx, Cedric (ed.). Minimalist Essays, 35-67. Amsterdam: Benjamins. $<$ https://doi.org/10.1075/la.91.08bib>

Biberauer, Theresa, Holmberg, Anders \& Roberts, Ian. 2014. A syntactic universal and its consequences. Linguistic Inquiry 45: 169-225. $<$ https://doi.org/10.1162/LING_a_00153>

Burzio, Luigi. 1986. Italian Syntax: a Government-Binding Approach. Dordrecht: Kluwer.

Cardinaletti, Anna. 2004. Towards a Cartography of Subject Positions. In Rizzi, Luigi (ed.). The Structure of CP and IP, 115-165. Oxford: Oxford University Press.

Cardinaletti, Anna. 2014. Cross-Linguistic Variation in the Syntax of Subjects. In Picallo, M. Carme (ed.). Linguistic Variation in the Minimalist Framework, 82-107. Oxford: Oxford University Press. $<$ https://doi.org/10.1093/acprof:oso/9780198702894.003.0005>

Cinque, Guglielmo. 1999. Adverbs and Functional Heads: A Cross-Linguistic Perspective. Oxford: Oxford University Press.

Costa, João. 2004. Subject Positions and Interfaces. Berlin: Mouton de Gruyter. $<$ https://doi.org/10.1515/9783110197396>

Danckaert, Lieven. 2012. Latin Embedded Clauses: The Left Periphery. Amsterdam: Benjamins. $<$ https://doi.org/10.1075/la.184>

Danckaert, Lieven. 2016. The Syntax-Prosody Mapping in a Dead Language: The Case of Late Latin BE-Periphrases. Paper presented at Going Romance 30, Frankfurt am Main, Johann Wolfgang Goethe-Universität, 10.12.2016.

Danckaert, Lieven. 2017a. The Development of Latin Clause structure: A Study of the Extended Verb Phrase. Oxford: Oxford University Press. $<$ https://doi.org/10.1093/oso/9780198759522.001.0001>

Danckaert, Lieven. 2017b. The Origins of the Romance Analytic Passive: Evidence from Word Order. In Mathieu, Eric \& Truswell, Robert (eds.). Micro-Change and Macro-Change in Diachronic Syntax, 216-235. Oxford: Oxford University Press. $<$ https://doi.org/10.1093/oso/9780198747840.001.0001>

Danckaert, Lieven. 2017c. The Loss of Latin OV: Steps towards an Analysis. In Aboh, Enoch, Haeberli, Eric, Puskás, Genoveva \& Schönenberger, Manuela (eds.). Elements of Comparative Syntax: Theory and Description, 401-446. Berlin: Mouton de Gruyter. $<$ https://doi.org/10.1515/9781501504037-015>

Danckaert, Lieven. to appear. The Decline of Latin VOAux: Neg-Incorporation and Syntactic Reanalysis. In Martins, Ana Maria \& Cardoso, Adriana (eds.). Word Order Change. Oxford: Oxford University Press.

Devine, Andrew \& Laurence Stephens. 2006. Latin Word Order: Structured Meaning and Information. Oxford: Oxford University Press. $<$ https://doi.org/10.1093/acprof:oso/9780195181685.001.0001>

Jayaseelan, Karattuparambil. 2010. Stacking, stranding and pied-piping: a proposal about word order. Syntax 13: 298-330.

$<$ https://doi.org/10.1111/j.1467-9612.2010.00141.x>

Kayne, Richard. 1994. The Antisymmetry of Syntax. Cambridge (Mass.): MIT Press. 
Kroch, Anthony. 1989. Reflexes of grammar in patterns of language change, Language Variation and Change 1, 199-244. $<$ https://doi.org/10.1017/S0954394500000168>

Kroch, Anthony. 1994. Morphosyntactic variation. In Beals, Katherine, Denton, Jeannette, Knippen, Robert, Melnar, Lynette, Suzuki, Hisami \& Zeinfeld, Erica (eds.). Papers from the Thirtieth Regional Meeting of the Chicago Linguistics Society, Volume 2: The Parasession on Variation in Linguistic Theory, 180-201. Chicago: Chicago Linguistics Society.

Lahousse, Karen. 2006. NP subject inversion in French: two types, two configurations. Lingua 116: 424-461. $<$ https://doi.org/10.1016/j.lingua.2004.08.020>

Lahousse, Karen. 2014. Low Sentence Structure in French. Paper presented at GLOW 37, Brussels, 04.04.2014.

Longobardi, Giuseppe. 2000. "Postverbal" subjects and the mapping hypothesis. Linguistic Inquiry 31: 691-702. $<$ https://doi.org/10.1162/002438900554514>

Mackenzie, Ian \& Wim van der Wurff. 2012. Relic syntax in Middle English and Medieval Spanish: parameter interaction in language change. Language 88: 846-876. $<$ https://doi.org/10.1353/lan.2012.0084>

Manetta, Emily. 2012. Reconsidering rightward scrambling: postverbal constituents in Hindi-Urdu. Linguistic Inquiry 43: 43-74. $<$ https://doi.org/10.1162/LING_a_00073>

Ordóñez, Francisco. 2007. Cartography of Postverbal Subjects in Spanish and Catalan. In Baauw, Sergio, Drijkoningen, Frank \& Pinto, Manuela (eds.). Romance Languages and Linguistic Theory 2005, 259-280. Amsterdam: Benjamins. $<$ https://doi.org/10.1075/cilt.291.17ord $>$

Rizzi, Luigi. 1982. Issues in Italian Syntax. Dordrect: Foris. $<$ https://doi.org/10.1515/9783110883718>

Simpson, Andrew \& Arunima Choudhury. 2015. The nonuniform syntax of postverbal elements in SOV languages: Hindi, Bangla, and the rightward scrambling debate. Linguistic Inquiry 46: 533-551.

$<$ https://doi.org/10.1162/LING_a_00191>

Wallenberg, Joel. 2015. Antisymmetry and Heavy NP Shift across Germanic. In Biberauer, Theresa \& Walkden, George (eds.). Syntax over Time: Lexical, Morphological and Information-Structural Interactions, 336-349. Oxford: Oxford University Press.

$<$ https://doi.org/10.1093/acprof:oso/9780199687923.001.0001>

Yang, Charles. 2000. Internal and external forces in language change. Language Variation and Change 12: 231-250. $<$ https://doi.org/10.1017/S0954394500123014>

Yang, Charles. 2002a. Knowledge and Learning in Natural Language. Oxford: Oxford University Press.

Yang, Charles. 2002b. Grammar Competition and Language Change. In Lightfoot, David (ed.). Syntactic Effects of Morphological Change, 367-409. Oxford: Oxford University Press.

<https://doi.org/10.1093/acprof:oso/9780199250691.003.0021> 
